\title{
Practice guideline update summary: Acute treatment of migraine in children and adolescents
}

Report of the Guideline Development, Dissemination, and Implementation Subcommittee of the American Academy of Neurology and the American

\section{Headache Society}

Maryam Oskoui, MD, MSc, Tamara Pringsheim, MD, Yolanda Holler-Managan, MD, Sonja Potrebic, MD, PhD, Lori Billinghurst, MD, MSc, David Gloss, MD, MPH\&TM, Andrew D. Hershey, MD, PhD, Nicole Licking, DO, Michael Sowell, MD, M. Cristina Victorio, MD, Elaine M. Gersz, Emily Leininger, Heather Zanitsch, Marcy Yonker, MD, and Kenneth Mack, MD, PhD

Neurology ${ }^{\circledR}$ 2019;93:487-499. doi:10.1212/WNL.0000000000008095

\section{Abstract \\ Objective}

To provide evidence-based recommendations for the acute symptomatic treatment of children and adolescents with migraine.

\section{Methods}

We performed a systematic review of the literature and rated risk of bias of included studies according to the American Academy of Neurology classification of evidence criteria. A multidisciplinary panel developed practice recommendations, integrating findings from the systematic review and following an Institute of Medicine-compliant process to ensure transparency and patient engagement. Recommendations were supported by structured rationales, integrating evidence from the systematic review, related evidence, principles of care, and inferences from evidence.

\section{Results}

There is evidence to support the efficacy of the use of ibuprofen, acetaminophen (in children and adolescents), and triptans (mainly in adolescents) for the relief of migraine pain, although confidence in the evidence varies between agents. There is high confidence that adolescents receiving oral sumatriptan/naproxen and zolmitriptan nasal spray are more likely to be headache-free at 2 hours than those receiving placebo. No acute treatments were effective for migraine-related nausea or vomiting; some triptans were effective for migraine-related phonophobia and photophobia.

\section{Recommendations}

Recommendations for the treatment of acute migraine in children and adolescents focus on the importance of early treatment, choosing the route of administration best suited to the characteristics of the individual migraine attack, and providing counseling on lifestyle factors that can exacerbate migraine, including trigger avoidance and medication overuse.

\author{
Correspondence \\ American Academy of \\ Neurology \\ guidelines@aan.com
}

\footnotetext{
From the Departments of Pediatrics and Neurology/Neurosurgery (M.O.), McGill University, Montréal, Canada; Departments of Clinical Neurosciences, Psychiatry, Pediatrics, and Community Health Sciences (T.P.), Cumming School of Medicine, University of Calgary, Canada; Department of Pediatrics (Neurology) (Y.-H.M.), Northwestern University Feinberg School of Medicine, Chicago, IL; Neurology Department (S.P.), Southern California Permanente Medical Group, Kaiser, Los Angeles; Division of Neurology (L.B.), Children's Hospital of Philadelphia, PA; Department of Neurology (D.G.), Charleston Area Medical Center, WV; Division of Neurology (A.D.H.), Cincinnati Children's Hospital Medical Center, OH; Department of Neuroscience and Spine (N.L.), St. Anthony Hospital-Centura Health, Lakewood, CO; University of Louisville Comprehensive Headache Program and University of Louisville Child Neurology Residency Program (M.S.), KY; Division of Neurology, NeuroDevelopmental Science Center (M.C.V.), Akron Children's Hospital, OH; Rochester (E.M.G.), NY; St. Paul (E.L.), MN; O'Fallon (H.Z.), MO; Division of Neurology (M.Y.), Children's Hospital Colorado, Aurora; and Department of Neurology (K.M.), Mayo Clinic, Rochester, MN.

Go to Neurology.org/N for full disclosures. Funding information and disclosures deemed relevant by the authors, if any, are provided at the end of the article.

Approved by the American Academy of Neurology (AAN) Guideline Development, Dissemination, and Implementation Subcommittee on October 20, 2018; by the AAN Practice Committee on March 29, 2019; by the AAN Institute Board of Directors on April 10, 2019; and by the American Headache Society Board of Directors on May 1, 2019.

This guideline was endorsed by the Child Neurology Society on February 9, 2019 and The American Academy of Pediatrics on April 8, 2019.
} 


\section{Glossary}

AAN = American Academy of Neurology; CI = confidence interval; FDA = Food and Drug Administration; NS = nasal spray; NSAID = nonsteroidal anti-inflammatory drug; ODT = oral disintegrating tablet; OS = oral solution; OT = oral tablet; RCT = randomized controlled trial; $\mathbf{R R}=$ relative risk.

This article summarizes the findings of a systematic review and practice recommendations for the acute treatment of migraine in children and adolescents. The complete practice guideline, including the risk of bias assessment for each study, metaanalysis, methods for analysis of the evidence, and confidence in evidence determinations, is available at https://www.aan. com/Guidelines/home/GetGuidelineContent/977.

Diagnosis of primary headache disorders is based on clinical criteria specified in the International Classification of Headache Disorders. ${ }^{1}$ Management of migraine includes acute and preventive therapies as well as behavioral and lifestyle changes. Acute treatments must be carefully selected and individually tailored to a patient's headache pattern, severity, and disability as well as their expectations, needs, and goals of treatment.

The purpose of this guideline is to systematically assess all randomized controlled trials (RCTs) that evaluated acute migraine treatments in children and adolescents. The guideline seeks to answer the following clinical question:

In children and adolescents with migraine, do acute selfadministered treatments, compared with placebo, reduce headache pain and associated symptoms (nausea, vomiting, photophobia, and phonophobia) and maintain headache freedom?

\section{Description of the analytic process}

The Guideline Development, Dissemination, and Implementation Subcommittee of the American Academy of Neurology (AAN) convened a multidisciplinary panel consisting of 12 AAN physician members and 3 patient representative members to develop this guideline according to the process described in the 2011 AAN guideline development process manual, ${ }^{2}$ as amended. The authors included RCTs on the acute pharmacologic treatment of migraine in children (individuals younger than 12 years) and adolescents (individuals aged 12-17 years). The authors considered studies published in English and in other languages. Trials of medications administered IV in the emergency department or in an infusion center setting were not included. The outcomes evaluated were reduction of headache pain and associated symptoms at specific time points. For headache pain, the most commonly reported outcomes were headache pain improvement, usually termed "headache pain response" and typically quantified as an improvement in intensity from moderate to severe pain to mild or no pain, and headache pain freedom, at specific time points after intervention (typically from 30 minutes to 2 hours). The most commonly reported associated symptoms were freedom from photophobia, phonophobia, nausea, or vomiting at specific time points after intervention.

This guideline updates a previous guideline published in 2004 on the treatment of migraine in children. The panel performed a literature search of articles published between December 1, 2003, and August 25, 2017. Two authors independently reviewed all abstracts and full-text articles for relevance. Articles were included if (1) at least $90 \%$ of study participants were aged $0-18$ years, (2) the study included a diagnosis of migraine, (3) the study had at least 20 participants, and (4) treatment was compared with placebo.

The authors found 2,482 abstracts relevant to acute or preventive therapy for pediatric migraine. The authors reviewed 313 full-text articles and identified 10 new studies of acute therapy to be included in the guideline. Of the 10 acute treatment studies included in the 2004 guideline on treatment of migraine in children, 6 were included in the current guideline; the other 4 studies were excluded because they were either Class IV (3 studies) or included fewer than 20 participants (1 study).

A modified Grading of Recommendations Assessment, Development and Evaluation process ${ }^{3}$ was used to develop conclusions. The confidence in the evidence (high, moderate, low, or very low) was anchored to the error domain-class of evidence, indirectness of evidence, and precision of effect estimate-with the highest risk of error. This confidence was upgraded or downgraded by a maximum of one level based on several other domains.

The panel formulated practice recommendations based on the strength of evidence and other factors, including axiomatic principles of care, the magnitude of anticipated health benefits relative to harms, financial burden, availability of interventions, and patient preferences. The panel assigned levels of obligation (A, B, C, U, R) to the recommendations, using a modified Delphi process. ${ }^{2}$

\section{Analysis of evidence}

Conclusions to the analysis of evidence are listed as follows. These conclusions are also summarized in tables 1-3. 


\section{Outcome: Pain response at 30 minutes}

Low confidence in the evidence

Adolescents receiving sumatriptan nasal spray (NS) $20 \mathrm{mg}$ are possibly more likely than those receiving placebo to have a headache pain response at 30 minutes (relative risk [RR] 1.27; $95 \%$ confidence interval $[\mathrm{CI}], 1.01-1.60 ; 1$ Class $\mathrm{I}^{4}$ study).

\section{Very low confidence in the evidence}

There is insufficient evidence to determine whether adolescents receiving sumatriptan NS $5 \mathrm{mg}$ are more or less likely than those receiving placebo to have a headache pain response at 30 minutes (RR 1.03; 95\% CI 0.80-1.32; 1 Class $\mathrm{I}^{4}$ study).

There is insufficient evidence to determine whether children and adolescents receiving the following treatments are more or less likely than those receiving placebo to have a headache pain response at 30 minutes:
- Sumatriptan oral tablet (OT) $25 \mathrm{mg}$ (RR 0.35; 95\% CI $0.03-4.14 ; 1$ Class I ${ }^{5}$ study)

- Sumatriptan OT 50 mg (RR 2.27; 95\% CI 0.58-8.90; 1 Class I ${ }^{5}$ study)

\section{Outcome: Pain response at 1 hour}

\section{Moderate confidence in the evidence}

Adolescents receiving sumatriptan NS $5 \mathrm{mg}$ are probably no more likely than those receiving placebo to have a headache pain response at 1 hour (RR 1.05; 95\% CI 0.91-1.21; 1 Class $\mathrm{I}^{4}$ and 1 Class $\mathrm{II}^{6}$ study).

\section{Low confidence in the evidence}

Children and adolescents receiving the following treatments are possibly more likely than those receiving placebo to have a headache pain response at 1 hour:

- Sumatriptan NS 10 mg (RR 1.55; 95\% CI 1.08-2.23; 2 Class II studies ${ }^{6,7}$ )

Table 1 Pain outcomes and confidence in evidence

\begin{tabular}{|c|c|c|c|c|c|c|}
\hline Outcome & $\begin{array}{l}\text { High } \\
\text { confidence } \\
\text { (more likely } \\
\text { than placebo) }\end{array}$ & $\begin{array}{l}\text { Moderate } \\
\text { confidence } \\
\text { (probably more } \\
\text { likely than placebo) }\end{array}$ & $\begin{array}{l}\text { Low confidence } \\
\text { (possibly more } \\
\text { likely than } \\
\text { placebo) }\end{array}$ & $\begin{array}{l}\text { Moderate confidence } \\
\text { (probably no more } \\
\text { likely than placebo) }\end{array}$ & $\begin{array}{l}\text { Low confidence } \\
\text { (possibly no more } \\
\text { likely than placebo) }\end{array}$ & $\begin{array}{l}\text { Very low } \\
\text { confidence } \\
\text { (insufficient } \\
\text { evidence) }\end{array}$ \\
\hline $\begin{array}{l}\text { Pain } \\
\text { response } \\
\text { at } 30 \\
\text { minutes }\end{array}$ & & & $\begin{array}{l}\text { Sumatriptan NS } \\
20 \mathrm{mg}\end{array}$ & & & $\begin{array}{l}\text { Sumatriptan NS } \\
5 \mathrm{mg} \\
\text { Sumatriptan OT } \\
25 \mathrm{mg} \\
\text { Sumatriptan OT } \\
50 \mathrm{mg}\end{array}$ \\
\hline $\begin{array}{l}\text { Pain } \\
\text { response } \\
\text { at } 1 \text { hour }\end{array}$ & & & $\begin{array}{l}\text { Zolmitriptan NS } \\
5 \mathrm{mg} \\
\text { Sumatriptan NS } \\
10 \mathrm{mg} \\
\text { Sumatriptan NS } \\
20 \mathrm{mg}\end{array}$ & Sumatriptan NS 5 mg & & $\begin{array}{l}\text { Sumatriptan OT } \\
25 \mathrm{mg} \\
\text { Sumatriptan OT } \\
50 \mathrm{mg}\end{array}$ \\
\hline $\begin{array}{l}\text { Pain } \\
\text { response } \\
\text { at } 2 \text { hours }\end{array}$ & & & $\begin{array}{l}\text { Ibuprofen OS } \\
7.5-10 \text { mg/kg } \\
\text { Acetaminophen OS } \\
15 \text { mg/kg } \\
\text { Almotriptan OT } \\
6.25 \text { mg } \\
\text { Almotriptan OT } \\
12.5 \text { mg } \\
\text { Sumatriptan NS } \\
20 \text { mg } \\
\text { Zolmitriptan NS } \\
5 \text { mg }\end{array}$ & $\begin{array}{l}\text { Rizatriptan ODT } 5 \text { or } \\
10 \mathrm{mg}\end{array}$ & Eletriptan OT 40 mg & $\begin{array}{l}\text { Almotriptan OT } \\
25 \text { mg } \\
\text { Sumatriptan NS } \\
5 \text { mg } \\
\text { Sumatriptan NS } \\
10 \text { mg } \\
\text { Sumatriptan OT } \\
25 \text { mg } \\
\text { Sumatriptan OT } \\
50 \text { mg }\end{array}$ \\
\hline $\begin{array}{l}\text { Pain-free } \\
\text { at } 1 \text { hour }\end{array}$ & & Zolmitriptan NS 5 mg & & & & \\
\hline $\begin{array}{l}\text { Pain-free } \\
\text { at } 2 \text { hours }\end{array}$ & $\begin{array}{l}\text { Sumatriptan } \\
\text { naproxen OT } \\
10 / 60 \mathrm{mg} \\
\text { Sumatriptan/ } \\
\text { naproxen OT } \\
30 / 180 \mathrm{mg} \\
\text { Sumatriptan/ } \\
\text { naproxen OT } \\
\text { 85/500 mg } \\
\text { Zolmitriptan NS } \\
5 \text { mg }\end{array}$ & $\begin{array}{l}\text { Ibuprofen OS 7.5-10 } \\
\text { mg/kg } \\
\text { Sumatriptan NS } 20 \text { mg }\end{array}$ & $\begin{array}{l}\text { Rizatriptan ODT } 5 \text { or } \\
10 \mathrm{mg}\end{array}$ & & $\begin{array}{l}\text { Almotriptan OT } \\
12.5 \mathrm{mg}\end{array}$ & $\begin{array}{l}\text { Acetaminophen } \\
\text { OS } 15 \text { mg/kg } \\
\text { Almotriptan OT } \\
6.25 \text { mg } \\
\text { Almotriptan OT } \\
25 \text { mg } \\
\text { Eletriptan OT } 40 \\
\text { mg } \\
\text { Sumatriptan OT } \\
25 \text { mg } \\
\text { Sumatriptan OT } \\
50 \text { mg }\end{array}$ \\
\hline
\end{tabular}

Abbreviations: NS = nasal spray; ODT = oral disintegrating tablet; OS = oral solution; OT = oral tablet. 
Table 2 Associated symptom outcomes and confidence in evidence

\begin{tabular}{|c|c|c|c|c|c|c|}
\hline Outcome & $\begin{array}{l}\text { High } \\
\text { confidence } \\
\text { (more likely } \\
\text { than placebo) }\end{array}$ & $\begin{array}{l}\text { Moderate } \\
\text { confidence } \\
\text { (probably more } \\
\text { likely than placebo) }\end{array}$ & $\begin{array}{l}\text { Low confidence } \\
\text { (possibly more } \\
\text { likely than } \\
\text { placebo) }\end{array}$ & $\begin{array}{l}\text { Moderate confidence } \\
\text { (probably no more } \\
\text { likely than placebo) }\end{array}$ & $\begin{array}{l}\text { Low confidence } \\
\text { (possibly no more } \\
\text { likely than } \\
\text { placebo) }\end{array}$ & $\begin{array}{l}\text { Very low } \\
\text { confidence } \\
\text { (insufficient } \\
\text { evidence) }\end{array}$ \\
\hline $\begin{array}{l}\text { Relief of } \\
\text { nausea at } 2 \\
\text { hours }\end{array}$ & & & & $\begin{array}{l}\text { Sumatriptan NS } 5 \text { mg } \\
\text { Sumatriptan NS } 20 \text { mg } \\
\text { Sumatriptan/ } \\
\text { naproxen OT 85/500 } \\
\text { mg }\end{array}$ & Eletriptan OT 40 mg & $\begin{array}{l}\text { Ibuprofen OS } \\
7.5-10 \mathrm{mg} / \mathrm{kg} \\
\text { Sumatriptan NS } \\
10 \mathrm{mg} \\
\text { Sumatriptan/ } \\
\text { naproxen OT } \\
10 / 60 \mathrm{mg} \\
\text { Sumatriptan/ } \\
\text { naproxen OT } \\
30 / 180 \mathrm{mg} \\
\text { Rizatriptan ODT } \\
5 \text { or } 10 \mathrm{mg}\end{array}$ \\
\hline $\begin{array}{l}\text { Relief of } \\
\text { vomiting at } 2 \\
\text { hours }\end{array}$ & & & & $\begin{array}{l}\text { Sumatriptan NS } 5 \text { mg } \\
\text { Sumatriptan NS } 20 \text { mg }\end{array}$ & $\begin{array}{l}\text { Sumatriptan NS } 10 \\
\text { mg } \\
\text { Rizatriptan ODT } 5 \text { or } \\
10 \text { mg }\end{array}$ & \\
\hline $\begin{array}{l}\text { Relief of } \\
\text { photophobia } \\
\text { at } 30 \text { minutes }\end{array}$ & & Zolmitriptan NS 5 mg & & & & \\
\hline $\begin{array}{l}\text { Relief of } \\
\text { photophobia } \\
\text { at } 2 \text { hours }\end{array}$ & & $\begin{array}{l}\text { Sumatriptan/ } \\
\text { naproxen OT 10/60 } \\
\text { mg } \\
\text { Sumatriptan/ } \\
\text { naproxen OT 85/500 } \\
\text { mg }\end{array}$ & $\begin{array}{l}\text { Zolmitriptan NS } 5 \\
\text { mg }\end{array}$ & & Eletriptan OT 40 mg & $\begin{array}{l}\text { Sumatriptan NS } \\
10 \mathrm{mg} \\
\text { Sumatriptan/ } \\
\text { naproxen OT } \\
30 / 180 \mathrm{mg} \\
\text { Rizatriptan ODT } \\
5 \text { or } 10 \mathrm{mg}\end{array}$ \\
\hline $\begin{array}{l}\text { Relief of } \\
\text { phonophobia } \\
\text { at } 30 \text { minutes }\end{array}$ & & Zolmitriptan NS 5 mg & & & & \\
\hline $\begin{array}{l}\text { Relief of } \\
\text { phonophobia } \\
\text { at } 2 \text { hours }\end{array}$ & & $\begin{array}{l}\text { Sumatriptan/ } \\
\text { naproxen OT 10/60 } \\
\text { mg } \\
\text { Sumatriptan/ } \\
\text { naproxen OT 85/500 } \\
\text { mg }\end{array}$ & $\begin{array}{l}\text { Sumatriptan NS } 5 \\
\text { mg } \\
\text { Sumatriptan NS } 20 \\
\text { mg } \\
\text { Sumatriptan/ } \\
\text { naproxen OT 30/ } \\
180 \text { mg }\end{array}$ & $\begin{array}{l}\text { Rizatriptan ODT } 5 \text { or } 10 \\
\text { mg }\end{array}$ & Eletriptan OT 40 mg & $\begin{array}{l}\text { Sumatriptan NS } \\
10 \mathrm{mg} \\
\text { Zolmitriptan NS } \\
5 \mathrm{mg}\end{array}$ \\
\hline
\end{tabular}

Abbreviations: NS = nasal spray; ODT = oral disintegrating tablet; OS = oral solution; OT = oral tablet.

- Sumatriptan NS 20 mg (RR 1.27; 95\% CI 1.09-1.49; 1 Class $\mathrm{I}^{4}$ and 2 Class II studies ${ }^{6,7}$ )

Adolescents receiving zolmitriptan NS $5 \mathrm{mg}$ are possibly more likely than those receiving placebo to have a headache pain response at 1 hour (RR 1.34; 95\% CI 1.05-1.71; 1 Class II study $\left.^{8}\right)$.

\section{Very low confidence in the evidence}

There is insufficient evidence to determine whether children and adolescents receiving the following treatments are more or less likely than those receiving placebo to have a headache pain response at 1 hour:

- Sumatriptan OT 25 mg (RR 0.49; 95\% CI 0.16-1.48; 1 Class I study ${ }^{5}$ )

- Sumatriptan OT 50 mg (RR 0.39; 95\% CI 0.13-1.19; 1 Class I study ${ }^{5}$ )

\section{Outcome: Pain response at 2 hours}

\section{Moderate confidence in the evidence}

Children and adolescents receiving 5 or $10 \mathrm{mg}$ of rizatriptan oral disintegrating tablets (ODT) are probably no more likely than those receiving placebo to have a headache pain response at 2 hours (RR 1.07; 95\% CI 0.97-1.17; 3 Class II studies ${ }^{9-11}$ ).

\section{Low confidence in the evidence}

Children and adolescents receiving the following treatments are possibly more likely than those receiving placebo to have a headache pain response at 2 hours:

- Ibuprofen oral solution (OS) $7.5-10 \mathrm{mg} / \mathrm{kg}$ (RR 1.54; 95\% CI 1.18-2.01; 1 Class II ${ }^{12}$ and 1 Class III ${ }^{13}$ study)

- Acetaminophen OS $15 \mathrm{mg} / \mathrm{kg}$ (RR 1.46; 95\% CI 1.02-2.09; 1 Class II study $\left.{ }^{12}\right)$

- Sumatriptan NS 20 mg (RR 1.32; 95\% CI 1.04-1.68; 1 Class $\mathrm{I}^{4}$ and 2 Class $\mathrm{II}^{6,7}$ studies) 
Table 3 Confidence in evidence by drug and outcome

\begin{tabular}{|c|c|c|c|c|c|c|c|c|c|}
\hline & $\begin{array}{l}\text { Pain } \\
\text { response } \\
\text { at } 30 \\
\text { minutes }\end{array}$ & $\begin{array}{l}\text { Pain } \\
\text { response } \\
\text { at } 1 \text { hour }\end{array}$ & $\begin{array}{l}\text { Pain } \\
\text { response } \\
\text { at } 2 \text { hours }\end{array}$ & $\begin{array}{l}\text { Pain-free } \\
\text { at } 1 \text { hour }\end{array}$ & $\begin{array}{l}\text { Pain-free } \\
\text { at } 2 \\
\text { hours }\end{array}$ & $\begin{array}{l}\text { Relief of } \\
\text { nausea at } \\
2 \text { hours }\end{array}$ & $\begin{array}{l}\text { Relief of } \\
\text { vomiting } \\
\text { at } 2 \text { hours }\end{array}$ & $\begin{array}{l}\text { Relief of } \\
\text { photophobia } \\
\text { at } 2 \text { hours }\end{array}$ & $\begin{array}{l}\text { Relief of } \\
\text { phonophobia } \\
\text { at } 2 \text { hours }\end{array}$ \\
\hline $\begin{array}{l}\text { Ibuprofen OS } \\
7.5-10 \mathrm{mg} / \mathrm{kg}\end{array}$ & & & Low & & Moderate & Very low & & & \\
\hline $\begin{array}{l}\text { Acetaminophen } \\
\text { OS } 15 \mathrm{mg} / \mathrm{kg}\end{array}$ & & & Low & & Very low & & & & \\
\hline $\begin{array}{l}\text { Sumatriptan OT } \\
25 \mathrm{mg}\end{array}$ & Very low & Very low & Very low & & Very low & & & & \\
\hline $\begin{array}{l}\text { Sumatriptan OT } \\
50 \mathrm{mg}\end{array}$ & Very low & Very low & Very low & & Very low & & & & \\
\hline $\begin{array}{l}\text { Sumatriptan NS } \\
5 \mathrm{mg}\end{array}$ & Very low & $\begin{array}{l}\text { Moderate: } \\
\text { probably } \\
\text { no more } \\
\text { likely than } \\
\text { placebo }\end{array}$ & Very low & & & $\begin{array}{l}\text { Moderate: } \\
\text { probably } \\
\text { no more } \\
\text { likely than } \\
\text { placebo }\end{array}$ & $\begin{array}{l}\text { Moderate: } \\
\text { probably } \\
\text { no more } \\
\text { likely than } \\
\text { placebo }\end{array}$ & Very low & Low \\
\hline $\begin{array}{l}\text { Sumatriptan NS } \\
10 \mathrm{mg}\end{array}$ & & Low & Very low & & & Very low & $\begin{array}{l}\text { Low: } \\
\text { possibly } \\
\text { no more } \\
\text { likely than } \\
\text { placebo }\end{array}$ & Very low & Very low \\
\hline $\begin{array}{l}\text { Sumatriptan NS } \\
20 \mathrm{mg}\end{array}$ & Low & Low & Low & & Moderate & $\begin{array}{l}\text { Moderate: } \\
\text { probably } \\
\text { no more } \\
\text { likely than } \\
\text { placebo }\end{array}$ & $\begin{array}{l}\text { Moderate: } \\
\text { probably } \\
\text { no more } \\
\text { likely than } \\
\text { placebo }\end{array}$ & Very low & Low \\
\hline $\begin{array}{l}\text { Sumatriptan/ } \\
\text { naproxen OT 10/ } \\
60 \mathrm{mg}\end{array}$ & & & & & High & Very low & & Moderate & Moderate \\
\hline $\begin{array}{l}\text { Sumatriptan/ } \\
\text { naproxen OT } 30 / \\
180 \mathrm{mg}\end{array}$ & & & & & High & Very low & & Very low & Low \\
\hline $\begin{array}{l}\text { Sumatriptan/ } \\
\text { naproxen OT } 85 \text { / } \\
500 \text { mg }\end{array}$ & & & & & High & $\begin{array}{l}\text { Moderate: } \\
\text { probably } \\
\text { no more } \\
\text { likely than } \\
\text { placebo }\end{array}$ & & Moderate & Moderate \\
\hline $\begin{array}{l}\text { Rizatriptan ODT } \\
5 \text { or } 10 \mathrm{mg}\end{array}$ & & & $\begin{array}{l}\text { Moderate: } \\
\text { probably } \\
\text { no more } \\
\text { likely than } \\
\text { placebo }\end{array}$ & & Low & Very low & $\begin{array}{l}\text { Low: } \\
\text { possibly } \\
\text { no more } \\
\text { likely than } \\
\text { placebo }\end{array}$ & Very low & $\begin{array}{l}\text { Moderate: } \\
\text { probably no } \\
\text { more likely } \\
\text { than placebo }\end{array}$ \\
\hline $\begin{array}{l}\text { Eletriptan ОT } 40 \\
\text { mg }\end{array}$ & & & $\begin{array}{l}\text { Low: } \\
\text { possibly } \\
\text { no more } \\
\text { likely than } \\
\text { placebo }\end{array}$ & & Very low & $\begin{array}{l}\text { Low: } \\
\text { possibly } \\
\text { no more } \\
\text { likely than } \\
\text { placebo }\end{array}$ & & $\begin{array}{l}\text { Low: possibly } \\
\text { no more likely } \\
\text { than placebo }\end{array}$ & $\begin{array}{l}\text { Low: possibly } \\
\text { no more likely } \\
\text { than placebo }\end{array}$ \\
\hline Zolmitriptan NS & & Low & Low & Moderate & High & & & Low & Very low \\
\hline $\begin{array}{l}\text { Almotriptan OT } \\
6.25 \mathrm{mg}\end{array}$ & & & Low & & Very low & & & & \\
\hline $\begin{array}{l}\text { Almotriptan OT } \\
12.5 \mathrm{mg}\end{array}$ & & & Low & & $\begin{array}{l}\text { Low: } \\
\text { possibly } \\
\text { no more } \\
\text { likely } \\
\text { than } \\
\text { placebo }\end{array}$ & & & & \\
\hline $\begin{array}{l}\text { Almotriptan ОT } \\
25 \mathrm{mg}\end{array}$ & & & Very low & & Very low & & & & \\
\hline
\end{tabular}

Abbreviations: NS = nasal spray; ODT = oral disintegrating tablet; OS = oral solution; OT = oral tablet. 
Adolescents receiving the following treatments are possibly more likely than those receiving placebo to have a headache pain response at 2 hours:

- Almotriptan OT 6.25 mg (RR 1.30; 95\% CI 1.10-1.53; 1 Class II study ${ }^{14}$ )

- Almotriptan OT 12.5 mg (RR 1.31; 95\% CI 1.11-1.54; 1 Class II study ${ }^{14}$ )

- Zolmitriptan NS 5 mg (RR 1.29; 95\% CI 1.06-1.58; 1 Class I study ${ }^{15}$ )

Adolescents receiving eletriptan OT $40 \mathrm{mg}$ are possibly no more likely than those receiving placebo to have a headache pain response at 2 hours (RR 0.99; 95\% CI 0.81-1.21; 1 Class II study ${ }^{16}$ ).

\section{Very low confidence in the evidence}

There is insufficient evidence to determine whether adolescents receiving the following treatments are more or less likely than those receiving placebo to have a headache pain response at 2 hours:

- Sumatriptan NS 5 mg (RR 1.14; 95\% CI 1.01-1.30; 1 Class $I^{4}$ and 1 Class II ${ }^{6}$ study)

- Almotriptan OT 25 mg (RR 1.21; 95\% CI 1.02-1.43; 1 Class II study ${ }^{14}$ )

There is insufficient evidence to determine whether children and adolescents receiving the following treatments are more or less likely than those receiving placebo to have a headache pain response at 2 hours:

- Sumatriptan NS 10 mg (RR 1.50; 95\% CI 0.93-2.41; 2 Class II studies ${ }^{6,7}$ )

- Sumatriptan OT 25 mg (RR 0.86; 95\% CI 0.48-1.46; 1 Class I study ${ }^{5}$ )

- Sumatriptan OT 50 mg (RR 0.76; 95\% CI 0.44-1.32; 1 Class I study ${ }^{5}$ )

\section{Outcome: Pain-free at 1 hour}

\section{Moderate confidence in the evidence}

Adolescents receiving zolmitriptan NS $5 \mathrm{mg}$ are probably more likely than those receiving placebo to be free of headache pain at 1 hour (RR 2.71; 95\% CI 1.54-4.78; 1 Class II study $\left.^{8}\right)$.

\section{Outcome: Pain-free at 2 hours}

\section{High confidence in the evidence}

Adolescents receiving the following treatments are more likely than those receiving placebo to be free of headache pain at 2 hours:

- Sumatriptan/naproxen OT 10/60 mg (RR 2.95; 95\% CI 1.65-5.27; 1 Class I study ${ }^{17}$ )

- Sumatriptan/naproxen OT 30/180 mg (RR 2.72; 95\% CI 1.51-4.89; 1 Class I study ${ }^{17}$ )
- Sumatriptan/naproxen OT 85/500 mg (RR 2.17; 95\% CI 1.49-3.16; 1 Class I ${ }^{17}$ and 1 Class $\mathrm{II}^{18}$ study)

- Zolmitriptan NS 5 mg (RR 1.90; 95\% CI 1.47-2.46; 1 Class I study ${ }^{15}$ and 1 Class II study ${ }^{8}$ )

\section{Moderate confidence in the evidence}

Children and adolescents receiving the following treatments are probably more likely than those receiving placebo to be free of headache pain at 2 hours:

- Ibuprofen OS 7.5-10 mg/kg (RR 2.15; 95\% CI $1.28-3.71,1$ Class II study $\left.{ }^{12}\right)$

- Sumatriptan NS 20 mg (RR 1.46; 95\% CI 1.21-1.77; 1 Class $\mathrm{I}^{4}$ and 2 Class II studies ${ }^{6,7}$ )

\section{Low confidence in the evidence}

Children and adolescents receiving rizatriptan ODT 5 or $10 \mathrm{mg}$ are possibly more likely than those receiving placebo to be free of headache pain at 2 hours (RR 1.28; 95\% CI 1.10-1.48; 3 Class II studies ${ }^{9-11}$ ).

Adolescents receiving almotriptan OT $12.5 \mathrm{mg}$ are possibly no more likely than those receiving placebo to be free of headache pain at 2 hours (RR 1.20; 95\% CI 0.91-1.58; 1 Class II study ${ }^{14}$ ).

\section{Very low confidence in the evidence}

There is insufficient evidence to determine whether children and adolescents receiving the following treatments are more or less likely than those receiving placebo to be free of headache pain at 2 hours:

- Acetaminophen OS $15 \mathrm{mg} / \mathrm{kg}$ (RR 1.40; 95\% CI $0.77-2.56,1$ Class II study ${ }^{12}$ )

- Sumatriptan OT 25 mg (RR 0.85; 95\% CI 0.42-1.46; 1 Class I study ${ }^{5}$ )

- Sumatriptan OT 50 mg (RR 0.68; 95\% CI 0.34-1.38; 1 Class I study ${ }^{5}$ )

There is insufficient evidence to determine whether adolescents receiving the following treatments are more or less likely than those receiving placebo to be free of headache pain at 2 hours:

- Almotriptan OT 6.25 mg (RR 1.04; 95\% CI 0.78-1.39; 1 Class II study ${ }^{14}$ )

- Almotriptan OT 25 mg (RR 1.18; 95\% CI 0.90-1.55; 1 Class II study ${ }^{14}$ )

- Eletriptan OT 40 mg (RR 1.46; 95\% CI 0.88-2.42; 1 Class II study ${ }^{16}$ )

\section{Outcome: Relief of nausea at 2 hours}

\section{Moderate confidence in the evidence}

Adolescents receiving the following treatments are probably no more likely than those receiving placebo to have relief of nausea at 2 hours: 
- Sumatriptan NS 5 mg (RR 1.03; 95\% CI 0.96-1.11; 1 Class $\mathrm{I}^{4}$ and 1 Class $\mathrm{II}^{6}$ study)

- Sumatriptan NS 20 mg (RR 1.02; 95\% CI 0.94-1.11; 1 Class I study ${ }^{4}$ )

Adolescents receiving sumatriptan/naproxen OT 85/500 mg are probably no more likely than those receiving placebo to be nausea-free at 2 hours (RR 1.00; 95\% CI 0.86-1.16; 1 Class I study $\left.^{17}\right)$.

\section{Low confidence in the evidence}

Adolescents receiving eletriptan ODT $40 \mathrm{mg}$ are possibly no more likely than those receiving placebo to be free of nausea at 2 hours (RR 0.96; 95\% CI 0.84-1.10; 1 Class II study $\left.^{16}\right)$.

\section{Very low confidence in the evidence}

There is insufficient evidence to determine whether children receiving ibuprofen OS $7.5-10 \mathrm{mg} / \mathrm{kg}$ are more or less likely than those receiving placebo to be free of nausea at 2 hours (RR 1.40; 95\% CI 1.00-1.96; 1 Class III study ${ }^{13}$ )

There is insufficient evidence to determine whether children and adolescents receiving rizatriptan ODT 5 or $10 \mathrm{mg}$ are more or less likely than those receiving placebo to be free of nausea at 2 hours (RR 1.11; 95\% CI 1.04-1.18; 1 Class II study $^{10}$ ).

There is insufficient evidence to determine whether adolescents receiving the following treatments are more or less likely than those receiving placebo to be free of nausea at 2 hours:

- Sumatriptan NS 5 mg (RR 1.19; 95\% CI 0.96 to 1.48 ; 1 Class II study)

- Sumatriptan NS 10 mg (RR 1.11; 95\% CI 0.97-1.27; 1 Class II study ${ }^{6}$ )

- Sumatriptan/naproxen OT 10/60 mg (RR 1.17; 95\% CI 1.01-1.35; 1 Class I study ${ }^{17}$ )

- Sumatriptan/naproxen OT 30/180 mg (RR 1.10; 95\% CI 0.94-1.28; 1 Class I study ${ }^{17}$ )

\section{Outcome: Relief of vomiting at $\mathbf{2}$ hours}

\section{Moderate confidence in the evidence}

Adolescents receiving the following treatments are probably no more likely than those receiving placebo to have relief of vomiting at 2 hours:

- Sumatriptan NS 5 mg (RR 1.01; 95\% CI 0.98-1.05; 1 Class I ${ }^{4}$ and 1 Class II $^{6}$ study)

- Sumatriptan NS 20 mg (RR 1.02, 95\% CI 0.99-1.05; 1 Class I study ${ }^{4}$ )

\section{Low confidence in the evidence}

Children and adolescents receiving the following treatments are possibly no more likely than those receiving placebo to have resolution of vomiting at 2 hours:
- Sumatriptan NS 10 mg (RR 1.00; 95\% CI 0.94-1.07; 1 Class II study ${ }^{6}$ )

- Rizatriptan ODT 5 or 10 mg (RR 1.02; 95\% CI 0.99-1.05; 1 Class II study ${ }^{10}$ )

\section{Outcome: Relief of photophobia at $\mathbf{3 0}$ minutes}

\section{Moderate confidence in the evidence}

Adolescents receiving zolmitriptan NS $5 \mathrm{mg}$ are probably more likely than those receiving placebo to be free of photophobia at 30 minutes (RR 1.66; 95\% CI 1.03-2.68; 1 Class II study ${ }^{8}$ ).

\section{Outcome: Relief of photophobia at 2 hours}

\section{Moderate confidence in the evidence}

Adolescents receiving the following treatments are probably more likely than those receiving placebo to be free of photophobia at 2 hours:

Sumatriptan/naproxen OT 10/60 mg (RR 1.45; 95\% CI 1.12-1.87; 1 Class I study ${ }^{17}$ )

- Sumatriptan/naproxen OT 85/500 mg (RR 1.44; 95\% CI 1.14-1.82; 1 Class I study ${ }^{17}$ )

\section{Low confidence in the evidence}

Adolescents receiving zolmitriptan NS $5 \mathrm{mg}$ are possibly more likely than those receiving placebo to be free of photophobia at 2 hours (RR 1.26; 95\% CI 1.05-1.51, 1 Class I study ${ }^{15}$ ).

Adolescents receiving eletriptan OT $40 \mathrm{mg}$ are possibly no more likely than those receiving placebo to be free of photophobia at 2 hours (RR 0.97; 95\% CI 0.85-1.10; 1 Class II study ${ }^{16}$ ).

\section{Very low confidence in the evidence}

There is insufficient evidence to determine whether adolescents receiving the following treatments are more or less likely than those receiving placebo to have resolution of photophobia at 2 hours:

- Sumatriptan NS 5 mg (RR 1.19; 95\% CI 0.96-1.48; 1 Class II study ${ }^{6}$ )

- Sumatriptan NS 10 mg (RR 1.10; 95\% CI 0.88-1.37; 1 Class II study ${ }^{6}$ )

- Sumatriptan NS 20 mg (RR 1.24; 95\% CI 1.00-1.54; 1 Class II study ${ }^{6}$ )

There is insufficient evidence to determine whether children and adolescents receiving the rizatriptan ODT 5 or $10 \mathrm{mg}$ are more or less likely than those receiving placebo to have resolution of photophobia at 2 hours (RR 1.11; 95\% CI 0.98-1.25; 1 Class II study ${ }^{10}$ ).

There is insufficient evidence to determine whether adolescents receiving sumatriptan/naproxen OT 30/180 mg are more or less likely than those receiving placebo to be free of 
photophobia at 2 hours (RR 1.19; 95\% CI 0.90-1.58; 1 Class I study $^{17}$ ).

\section{Outcome: Relief of phonophobia at $\mathbf{3 0}$ minutes}

\section{Moderate confidence in the evidence}

Adolescents receiving zolmitriptan NS $5 \mathrm{mg}$ are probably more likely than those receiving placebo to be free of phonophobia at 30 minutes (RR 1.68; 95\% CI 1.03-2.74; 1 Class II study ${ }^{8}$ ).

\section{Outcome: Relief of phonophobia at 2 hours}

\section{Moderate confidence in the evidence}

Adolescents receiving the following treatments are probably more likely than those receiving placebo to be free of phonophobia at 2 hours:

- Sumatriptan/naproxen OT 10/60 mg (RR 1.45; 95\% CI 1.13-1.87; 1 Class I study ${ }^{17}$ )

- Sumatriptan/naproxen OT 85/500 mg (RR 1.43; 95\% CI 1.14-1.80; 1 Class I study ${ }^{17}$ )

Children and adolescents receiving the rizatriptan ODT 5 or $10 \mathrm{mg}$ are probably no more likely than those receiving placebo to be free of phonophobia at 2 hours (RR 1.07; 95\% CI 0.97-1.18; 2 Class II studies ${ }^{10,11}$ ).

\section{Low confidence in the evidence}

Adolescents receiving sumatriptan/naproxen OT 30/180 are possibly more likely than those receiving placebo to be free of phonophobia at 2 hours (RR 1.38; 95\% CI 1.07-1.78; 1 Class I study ${ }^{17}$ ).

Adolescents receiving the following treatments are possibly more likely than those receiving placebo to be free of phonophobia at 2 hours:

- Sumatriptan NS 5 mg (RR 1.29; 95\% CI 1.07-1.56; 1 Class II study ${ }^{6}$ )

- Sumatriptan NS 20 mg (RR 1.34; 95\% CI 1.11-1.62; 1 Class II study ${ }^{6}$ )

Adolescents receiving eletriptan OT $40 \mathrm{mg}$ are possibly no more likely than those receiving placebo to be free of phonophobia at 2 hours (RR 1.05; 95\% CI 0.89-1.24; 1 Class II study $\left.^{16}\right)$.

\section{Very low confidence in the evidence}

There is insufficient evidence to determine whether adolescents receiving the following treatments are more or less likely than those receiving placebo to have resolution of phonophobia at 2 hours:

- Sumatriptan NS 10 mg (RR 1.20; 95\% CI 0.99-1.46; 1 Class II study ${ }^{6}$ )

- Zolmitriptan NS 5 mg (RR 1.21; 95\% CI 1.02-1.44; 1 Class I study ${ }^{15}$ )

\section{Practice recommendations}

\section{Establish a specific headache diagnosis}

\section{Recommendation 1 rationale}

The appropriate care of a patient with headaches requires establishing a correct diagnosis. This affects our diagnostic approach, treatment, and prognosis. Patients with signs and symptoms of secondary headache, such as sudden change in headache, papilledema, focal deficits, and the additional presence of seizures, require further evaluation beyond a thorough history and physical examination. When migraine is diagnosed, tailored treatments may be considered that can result in improved outcomes. ${ }^{19}$ Diagnostic criteria for pediatric migraine include at least 5 headaches over the last year that last 2-72 hours when untreated, with 2 of 4 additional features (pulsatile quality, unilateral, worsening with activity or limiting activity, moderate to severe in intensity), and association with at least nausea, vomiting, photophobia, or phonophobia. These associated symptoms can be inferred by family report of the child's activities. The time a child sleeps can be considered part of the headache duration. Auras typically occur in about one third of older children and adolescents and precede the headache by $5-60$ minutes. ${ }^{1}$

\section{Statement $1 a$}

When evaluating children and adolescents with headache, clinicians should diagnose a specific headache type (primary, secondary, or other headache syndrome) (Level B).

\section{Statement $1 b$}

When evaluating children and adolescents with headache, clinicians should ask about premonitory and aura symptoms, headache semiology (onset, location, quality, severity, frequency, duration, and aggravating and alleviating factors), associated symptoms (nausea, vomiting, phonophobia, and photophobia), and pain-related disability in order to improve diagnostic accuracy for migraine and appropriately counsel the patient (Level B).

\section{Acute migraine treatment}

\section{Recommendation 2 rationale}

Migraine treatment should aim to achieve fast, complete pain relief, with minimum side effects. Associated symptoms like nausea, vomiting, photophobia, and phonophobia should also be addressed. In adults, early treatment of migraine (within less than 1 hour of headache onset) improves pain-free rates. ${ }^{20}$ Improved efficacy with early treatment is likely to be seen in children and adolescents as well. Many children and adolescents use and benefit from nonprescription oral analgesics like acetaminophen, ibuprofen, and naproxen. ${ }^{21}$ Triptans are less commonly prescribed in children than in adults, and only almotriptan (for patients aged 12 years and older), rizatriptan (for patients aged 6-17 years), sumatriptan/naproxen (for patients aged 12 years and older), and zolmitriptan NS (for patients aged 12 years and older) are approved by the Food and Drug Administration (FDA) for use in children. Ergots and oral naproxen alone have not been studied in children. 


\section{Statement $2 a$}

Clinicians should counsel that acute migraine treatments are more likely to be effective when used earlier in the migraine attack, when pain is still mild (Level B).

\section{Statement $2 b$}

Clinicians should prescribe ibuprofen OS $(10 \mathrm{mg} / \mathrm{kg})$ as an initial treatment option to reduce pain in children and adolescents with migraine (Level B)

\section{Statement 2c}

For adolescents with migraine, clinicians should prescribe sumatriptan/naproxen OT (10/60, 30/180, 85/500 mg), zolmitriptan NS (5 mg), sumatriptan NS (20 mg), rizatriptan ODT (5 or $10 \mathrm{mg}$ ), or almotriptan OT (6.25 or $12.5 \mathrm{mg}$ ) to reduce headache pain (Level $B$ ).

\section{Recommendation 3 rationale}

Patients respond differently to the same medication. In adults, failure to respond to 1 triptan does not preclude response to an alternate triptan. ${ }^{22}$ In adults who respond to a triptan but have recurrence of their headache within 24 hours, taking a second dose is effective. ${ }^{23}$ Children might have the same experience, but product monograph daily maximum doses must be followed. Migraine features (severity, associated symptoms, disability, and most bothersome symptoms) differ among individuals and among different attacks in the same individual. ${ }^{24}$ Intranasal sumatriptan and zolmitriptan are absorbed more quickly than the oral form ${ }^{25,26}$ and have a faster onset of action. ${ }^{27,28}$ For migraines that rapidly peak in severity or are associated with nausea and vomiting, nonoral forms of treatment may be more effective. Thus, children with migraine may benefit from more than 1 acute treatment choice and different delivery routes, depending on their individual headache characteristics.

\section{Statement $3 a$}

Clinicians should counsel patients and families that a series of medications may need to be used to find treatments that most benefit the patient (Level B).

\section{Statement $3 b$}

Clinicians should instruct patients and families to use the medication that best treats the characteristics of each migraine to provide the best balance of efficacy, side effects, and patient preference (Level B).

\section{Statement $3 c$}

Clinicians should offer an alternate triptan, if 1 triptan fails to provide pain relief, to find the most effective agent to reduce migraine symptoms (Level B).

\section{Statement 3d}

Clinicians may prescribe a nonoral route when headache peaks in severity quickly, is accompanied by nausea or vomiting, or oral formulations fail to provide pain relief (Level C).

\section{Statement $3 e$}

Clinicians should counsel patients and families that if their headache is successfully treated by their acute migraine medication but headache recurs within 24 hours of their initial treatment, taking a second dose of acute migraine medication can treat the recurrent headache (Level B).

\section{Recommendation 4 rationale}

Sumatriptan/naproxen OT (10/60, 30/180, and 85/500 mg) is more likely than placebo to result in headache pain-free status at 2 hours. Sumatriptan and naproxen have different pharmacokinetic profiles targeted to aid in migraine relief. ${ }^{29}$ In adults, the sumatriptan/naproxen combination OT is more effective than monotherapy with either component. ${ }^{30} \mathrm{Be}-$ cause of cost and insurance issues, not all patients have access to all available formulations of medications. Given the distinct mechanisms of action among medications in the triptan class and the nonsteroidal anti-inflammatory drug (NSAID) class, the addition of an NSAID to a triptan may improve rates of pain response and pain-free status.

\section{Statement 4}

In adolescents whose migraine is incompletely responsive to a triptan, clinicians should offer ibuprofen or naproxen in addition to a triptan to improve migraine relief (Level B).

\section{Treatment of associated symptoms}

\section{Recommendation 5 rationale}

Migraine is typically accompanied by other symptoms (nausea, vomiting, photophobia, phonophobia) in addition to head pain. Antiemetics are often prescribed along with specific (triptan) and nonspecific (NSAID) migraine treatments to address nausea and vomiting and to speed the rate of medication absorption. In pediatric migraine trials, the treatment effects on migraineassociated symptoms were less pronounced than the treatment effects on pain. While photophobia and phonophobia were responsive to zolmitriptan NS and sumatriptan/naproxen, none of the treatments studied had demonstrated effectiveness against nausea or vomiting. Antiemetics are available to treat nausea and vomiting related to other pediatric conditions (acute gastroenteritis, postoperative state, chemotherapy) $)^{31,32}$ and may be of benefit for migraine-associated nausea, although no clinical trials specifically evaluating antiemetics for pediatric migraineassociated nausea have been performed. NS formulations of zolmitriptan and sumatriptan may be easier to administer in adolescents with migraine with prominent nausea or vomiting.

\section{Statement 5}

For children and adolescents with migraine who experience prominent nausea or vomiting, clinicians should offer additional antiemetic treatments (Level B).

\section{Counseling}

\section{Recommendation 6 rationale}

Patient education can improve patient safety and adherence to interventions. It is important to learn about the behavioral 
aspects of self-care that might improve migraine, including healthy habits with lifestyle modification, potential migraine triggers/aggravating factors, and the risk of overusing medication. Maintaining a headache diary is helpful to track response to any new therapy. Patients and families will benefit from understanding the limitations of current available treatments. Overuse of medication to treat acute attacks has been associated with medication overuse headache in adults ${ }^{33}$ but has not been well-studied in children. Methods to prevent medication overuse headache are included in adult treatment plans.

\section{Statement $6 a$}

Clinicians should counsel children and adolescents with migraine and their families about migraine-healthy habits, including lifestyle modification, identification/disproof/resolution of migraine triggers/aggravating factors, and avoidance of medication overuse (Level B).

\section{Statement $6 b$}

Clinicians should make collaborative agreements with children and adolescents with migraine and their families on treatment goals that are individualized to the patient (Level B).

\section{Statement $6 c$}

Clinicians may counsel children and adolescents with migraine and their families to maintain a headache diary to monitor their response to treatments (Level C).

\section{Statement 6d}

Clinicians should counsel patients and families to use no more than 14 days of ibuprofen or acetaminophen per month, no more than 9 days of triptans per month, and no more than 9 days per month of any combination of triptans, analgesics, or opioids for more than 3 months to avoid medication overuse headache (Level B). (There is no evidence to support the use of opioids in children with migraine. Opioids are included in this statement to be consistent with the International Classification of Headache Disorders ${ }^{1}$ regarding medication overuse.)

\section{Contraindications and precautions to triptan use}

\section{Recommendation 7 rationale}

According to the FDA, triptans are contraindicated in patients with a history of cardiovascular disease, including stroke, TIA, myocardial infarction, severe peripheral vascular disease, ischemic bowel disease, and coronary vasospasm, including Prinzmetal angina. Triptans are also contraindicated in patients with cardiac accessory conduction pathway disorders, including Wolff-Parkinson-White syndrome. Although the 2004 American Headache Society consensus statement does not consider these as absolute contraindications, ${ }^{34}$ these contraindications are based on the known pharmacology of the triptans ${ }^{35}$ and triptan effects on vascular muscle. ${ }^{36}$ While these medical contraindications are less prevalent in the pediatric population, they are important to consider.

\section{Statement 7}

Clinicians must not prescribe triptans to those with a history of ischemic vascular disease or accessory conduction pathway disorders to avoid the morbidity and mortality associated with aggravating these conditions (Level A).

\section{Recommendation 8 rationale}

In adults who have migraine with typical aura, there is evidence that it is safe to take triptans during the aura, although the triptan may be more effective if taken at the onset of pain. ${ }^{37,38}$ The use of triptans during the aura phase is of concern because of potential difficulties differentiating early stroke symptoms from migraine aura. While this is unlikely a problem in those with established migraine with visual aura, caution is warranted in those with more complex aura presentations. According to the FDA, triptans are contraindicated in those with a history of hemiplegic aura or migraine with brainstem aura. This contraindication was based on a view of migraine pathophysiology that is no longer considered current.

\section{Statement $8 a$}

Clinicians should counsel adolescent patients with migraine with aura that taking their triptan during a typical aura is safe, but that the triptan may be more effective if taken at the onset of head pain (Level B).

\section{Statement $8 b$}

Clinicians may consider referral of children and adolescents with hemiplegic migraine or migraine with brainstem aura who do not respond to other treatments to a headache specialist to find effective treatment (Level C).

\section{Suggestions for future research}

Most adults with migraine have onset in childhood or adolescence. Accurate diagnosis and treatment in childhood and adolescence can prevent migraine-related disability and significantly improve quality of life. ${ }^{19}$ Lifestyle modifications and acute pharmacologic treatments are the mainstay of management. Although the pathophysiology of migraine is presumed to be the same as in adults, a higher placebo response is observed in children and adolescents, with a lower therapeutic gain measured in clinical trials. ${ }^{39}$ Patterns of migraine presentation and associated symptoms in children and adolescents evolve into the adult patterns and their shortest headaches may be shorter in duration. ${ }^{1}$ These factors should be considered when designing clinical trials. The fact that all acute treatment trials in children and adolescents are performed after proven efficacy in adults may be a contributor to the expectation response adding to the placebo effect. This expectation response is widely seen in pain studies and may explain why so few trials of acute migraine therapy in children and adolescents have shown positive results.

Although there is a growing body of evidence to support recommendations for the acute treatment of pediatric 
migraine, challenges remain. Many children and adolescents do not respond to treatment at home with NSAIDs and triptans and seek pain relief at an emergency department or infusion center. ${ }^{40}$ Trials of refractory headache treatment in children and adolescents have been conducted ${ }^{41}$ but therapeutic approaches in these circumstances vary. ${ }^{42}$ Studies are also needed of alternate delivery routes for acute treatments such as transdermal patches because oral medications are poorly absorbed in children and adolescents with nausea and vomiting. Regardless of the strategy chosen for acute migraine therapy, treatment plans should be individually tailored to the patient and family and include education about migraine prevention strategies.

\section{Author contributions}

Dr. Oskoui: study concept and design, acquisition of data, analysis or interpretation of data, drafting/revising the manuscript, critical revision of the manuscript for important intellectual content, study supervision. Dr. HollerManagan: study concept and design, acquisition of data, analysis or interpretation of data, revising the manuscript. Dr. Pringsheim: study concept and design, acquisition of data, analysis or interpretation of data, drafting/revising the manuscript, critical revision of the manuscript for important intellectual content, study supervision. Dr. Potrebic: study concept and design, acquisition of data, analysis or interpretation of data, drafting/revising the manuscript, critical revision of the manuscript for important intellectual content, study supervision. Dr. Billinghurst: analysis or interpretation of data, drafting/revising the manuscript, critical revision of the manuscript for important intellectual content, study supervision. Dr. Gloss: study concept and design, acquisition of data, analysis or interpretation of data, drafting/revising the manuscript. Dr. Hershey: study concept and design, interpretation of data, drafting/ revising the manuscript, critical revision of the manuscript for important intellectual content. Dr. Licking: acquisition of data, interpretation of data, revising the manuscript. Dr. Sowell: interpretation of data revising the manuscript. Dr. Victorio: interpretation of data, revising the manuscript. E.M. Gersz: study concept, interpretation of data, revising the manuscript. E. Leininger: study concept, interpretation of data, revising the manuscript. $\mathrm{H}$. Zanitsch: study concept, interpretation of data, revising the manuscript. Dr. Yonker: study concept, interpretation of data, revising the manuscript. Dr. Mack: study design and concept, interpretation of data, drafting/revising the manuscript, critical revision of manuscript for important intellectual content.

\section{Study funding}

This practice guideline was developed with financial support from the AAN. Authors who serve or have served as AAN subcommittee members or as methodologists (M.O., Y.H.M., T.P., S.P., L.B., D.G., and N.L.) were reimbursed by the AAN for expenses related to travel to subcommittee meetings where drafts of manuscripts were reviewed. All authors on the panel were reimbursed by the AAN for expenses related to travel to in-person meetings.

\section{Disclosure}

M. Oskoui reports no disclosures relevant to the manuscript. Y. Holler-Managan serves on the editorial advisory board for Neurology Now. T. Pringsheim reports no disclosures relevant to the manuscript. S. Potrebic has received funding from the AAN for travel to biennial Guidelines International Network meetings by the AAN; has received an honorarium and funding for travel to serve as an expert from the Center for Diagnostic Imaging and Insight Imaging (CDI) Quality Institute for work on Appropriate Use Criteria for headache imaging; and has received an honorarium from the California Technology Assessment Forum for participation as expert reviewer of the Institute for Clinical and Economic Review Calcitonin Gene-Related Peptide (CGRP) Inhibitors as Preventive Treatments for Patients with Episodic or Chronic Migraine: Effectiveness and Value Final Evidence Report. L. Billinghurst and D. Gloss report no disclosures relevant to the manuscript. A. Hershey has served on a scientific advisory board for Allergan, XOC Pharma, and Amgen; served as an editor for Headache, Cephalalgia, and the Journal of Headache and Pain; has received compensation from Allergan and MAP Pharma and currently receives compensation from Alder, Amgen, Avanir, Curelator, Depomed, Impax, Lilly, Supernus, and Upsher-Smith for serving on speakers' bureaus and as a medical consultant; has received research support from GlaxoSmithKline for serving as a Local Site PI on a study on pediatric migraine treatment, from the Migraine Research Foundation and Curelator, Inc. for serving as a principal investigator on studies on migraine genomics and diagnosis, and from the National Headache Foundation for serving as a coinvestigator on a study on migraine prognosis; has received grants from the National Institutes of Health/National Institute of Neurologic Disorders and Stroke (NINDS) for serving as a coinvestigator on a study on migraine management, studies on treatment, prognosis, and diagnosis of pediatric chronic migraine and headache, and for serving as a dual principal investigator on a study on amitriptyline and topiramate in the prevention of childhood migraine; and serves as a board member of the American Headache Society. N. Licking has no relevant disclosures for this guideline. M. Sowell has received compensation for serving on a speakers' bureau for Amgen/Novartis Pharmaceuticals; has served as manuscript editor for the journal Headache and the Journal of Child Neurology, on a speakers' bureau for Allergan, and as an interviewer for Neurology podcasts; served as site principal investigator for the CHAMP (Childhood and Adolescent Migraine Prevention) study, for which he received research support from NINDS; and receives research support from Impax Pharmaceuticals. M.C. Victorio is the site primary investigator for a childhood and adolescent migraine prevention study funded by the NIH and site investigator for a pediatric migraine treatment study funded by Impax Laboratories (both studies were contracted through Akron Children's Hospital); has received funding for travel to meetings of the 
Registry Committee and Quality and Safety Subcommittee by the AAN; has received honoraria for authoring and coauthoring chapters in the Merck Manual and for authoring an article in Pediatric Annals; and performs the following clinical procedures in her practice: onabotulinumtoxinA injection for chronic migraine $(2 \%)$ and peripheral nerve block injections (2\%). E. Gersz and E. Leininger report no disclosures relevant to the manuscript. H. Zanitsch has received financial compensation from the Patient-Centered Outcomes Research Institute and Peer Reviewed Medical Research Program and serves as a volunteer advocate for the National Headache Foundation. M. Yonker has served on a scientific advisory board for AMGEN and for Upsher-Smith Pharmaceuticals; has served as a reviewer for Cephalalgia, Headache, Pediatrics, and the Journal of the Child Neurology Society; has received research support as a primary investigator from AstraZeneca, Allergan, Avanir, and NINDS; has received funding for travel from the American Headache Society for serving as a presenter at the Scottsdale Headache Symposium; and serves as a consultant to Impax. Dr. Kenneth Mack has served as an advisor for AMGEN; receives publishing royalties from UpToDate; performs botulinum toxin injections for headache treatment as $5 \%$ of his clinical effort; and serves as a member of the Neurology ${ }^{\circledR}$ editorial board. Go to Neurology.org/N for full disclosures.

\section{Disclaimer}

Practice guidelines, practice advisories, comprehensive systematic reviews, focused systematic reviews, and other guidance published by the AAN and its affiliates are assessments of current scientific and clinical information provided as an educational service. The information (1) should not be considered inclusive of all proper treatments, methods of care, or as a statement of the standard of care; (2) is not continually updated and may not reflect the most recent evidence (new evidence may emerge between the time information is developed and when it is published or read); (3) addresses only the question(s) specifically identified; (4) does not mandate any particular course of medical care; and (5) is not intended to substitute for the independent professional judgment of the treating provider, as the information does not account for individual variation among patients. In all cases, the selected course of action should be considered by the treating provider in the context of treating the individual patient. Use of the information is voluntary. AAN provides this information on an "as is" basis and makes no warranty, expressed or implied, regarding the information. AAN specifically disclaims any warranties of merchantability or fitness for a particular use or purpose. AAN assumes no responsibility for any injury or damage to persons or property arising out of or related to any use of this information or for any errors or omissions.

\section{Conflict of interest}

The AAN is committed to producing independent, critical, and truthful clinical practice guidelines (CPGs). Significant efforts are made to minimize the potential for conflicts of interest to influence the recommendations of this CPG. To the extent possible, the AAN keeps separate those who have a financial stake in the success or failure of the products appraised in the CPGs and the developers of the guidelines. Conflict of interest forms were obtained from all authors and reviewed by an oversight committee prior to project initiation. AAN limits the participation of authors with substantial conflicts of interest. The AAN forbids commercial participation in, or funding of, guideline projects. Drafts of the guideline have been reviewed by at least 3 AAN committees, a network of neurologists, Neurology peer reviewers, and representatives from related fields. The AAN Guideline Author Conflict of Interest Policy can be viewed at aan.com. For complete information on this process, access the 2011 AAN process manual, as amended. $^{2}$

\section{Publication history}

Received by Neurology December 17, 2018. Accepted in final form May 14, 2019.

\section{References}

1. Headache Classification Committee of the International Headache Society. The International Classification of Headache Disorders, 3rd edition (beta version). Cephalalgia 2013;33:629-808.

2. American Academy of Neurology. Clinical Practice Guideline Process Manual. St. Paul: The American Academy of Neurology; 2011.

3. Guyatt GH, Oxman AD, Vist GE, et al. GRADE: an emerging consensus on rating quality of evidence and strength of recommendations. BMJ 2008;336: 924-926.

4. Winner P, Rothner AD, Wooten JD, Webster C, Ames M. Sumatriptan nasal spray in adolescent migraineurs: a randomized, double-blind, placebo-controlled, acute study. Headache 2006;46:212-222.

5. Fujita M, Sato K, Nishioka H, Sakai F. Oral sumatriptan for migraine in children and adolescents: a randomized, multicenter, placebo-controlled, parallel group study. Cephalalgia 2014;34:365-375.

6. Winner P, Rothner AD, Saper J, et al. A randomized, double-blind, placebo-controlled study of sumatriptan nasal spray in the treatment of acute migraine in adolescents. Pediatrics 2000;106:989-997.

7. Ahonen K, Hamalainen ML, Rantala H, Hoppu K. Nasal sumatriptan is effective in treatment of migraine attacks in children: a randomized trial. Neurology 2004;62: 883-887.

8. Lewis DW, Winner P, Hershey AD, Wasiewski WW; Adolescent Migraine Steering Committee. Efficacy of zolmitriptan nasal spray in adolescent migraine. Pediatrics 2007;120:390-396.

9. Visser WH, Winner P, Strohmaier K, et al. Rizatriptan $5 \mathrm{mg}$ for the acute treatment of migraine in adolescents: results from a double-blind, single-attack study and two open-label, multiple-attack studies. Headache 2004;44:891-899.

10. Ho TW, Pearlman E, Lewis D, et al. Efficacy and tolerability of rizatriptan in pediatric migraineurs: results from a randomized, double-blind, placebo-controlled trial using a novel adaptive enrichment design. Cephalalgia 2012;32:750-765.

11. Winner P, Lewis D, Visser WH, Jiang K, Ahrens S, Evans JK. Rizatriptan $5 \mathrm{mg}$ for the acute treatment of migraine in adolescents: a randomized double-blind, placebocontrolled study. Headache 2002;42:49-55.

12. Hamalainen ML, Hoppu K, Valkeila E, Santavuori P. Ibuprofen or acetaminophen for the acute treatment of migraine in children: a double-blind, randomized, placebocontrolled, crossover study. Neurology 1997;48:103-107.

13. Lewis DW, Kellstein D, Dahl G, et al. Children's ibuprofen suspension for the acute treatment of pediatric migraine. Headache 2002;42:780-786.

14. Linder SL, Mathew NT, Cady RK, Finlayson G, Ishkanian G, Lewis DW. Efficacy and tolerability of almotriptan in adolescents: a randomized, double-blind, placebocontrolled trial. Headache 2008;48:1326-1336.

15. Winner P, Farkas V, Stillova H, et al. Efficacy and tolerability of zolmitriptan nasal spray for the treatment of acute migraine in adolescents: results of a randomized, double-blind, multi-center, parallel-group study (TEENZ). Headache 2016;56:1107-1119.

16. Winner P, Linder SL, Lipton RB, Almas M, Parsons B, Pitman V. Eletriptan for the acute treatment of migraine in adolescents: results of a double-blind, placebocontrolled trial. Headache 2007;47:511-518.

17. Derosier FJ, Lewis D, Hershey AD, et al. Randomized trial of sumatriptan and naproxen sodium combination in adolescent migraine. Pediatrics 2012;129: e1411-1420.

18. Winner P, Linder S, Hershey AD. Consistency of response to sumatriptan/naproxen sodium in a randomized placebo-controlled, cross-over study for the acute treatment of migraine in adolescence. Headache 2015;55:519-528. 
19. Hershey AD. Current approaches to the diagnosis and management of paediatric migraine. Lancet Neurol 2010;9:190-204.

20. Lanteri-Minet M, Mick G, Allaf B. Early dosing and efficacy of triptans in acute migraine treatment: the TEMPO study. Cephalalgia 2012;32:226-235.

21. Bigal ME, Lipton RB, Winner P, et al. Migraine in adolescents: association with socioeconomic status and family history. Neurology 2007;69:16-25.

22. Farkkila M, Olesen J, Dahlof C, et al. Eletriptan for the treatment of migraine in patients with previous poor response or tolerance to oral sumatriptan. Cephalalgia 2003;23:463-471.

23. Ferrari MD, James MH, Bates D, et al. Oral sumatriptan: effect of a second dose, and incidence and treatment of headache recurrences. Cephalalgia 1994;14:330-338.

24. Buse DC, Loder EW, Gorman JA, et al. Sex differences in the prevalence, symptoms, and associated features of migraine, probable migraine and other severe headache: results of the American Migraine Prevalence and Prevention (AMPP) Study. Headache 2013;53:1278-1299.

25. Duquesnoy C, Mamet JP, Sumner D, Fuseau E. Comparative clinical pharmacokinetics of single doses of sumatriptan following subcutaneous, oral, rectal and intranasal administration. Eur J Pharm Sci 1998;6:99-104.

26. Uemura N, Onishi T, Mitaniyama A, et al. Bioequivalence and rapid absorption of zolmitriptan nasal spray compared with oral tablets in healthy Japanese subjects. Clin Drug Invest 2005;25:199-208.

27. Tfelt-Hansen P Efficacy and adverse events of subcutaneous, oral, and intranasal sumatriptan used for migraine treatment: a systematic review based on number needed to treat. Cephalalgia 1998;18:532-538.

28. Charlesworth BR, Dowson AJ, Purdy A, Becker WJ, Boes-Hansen S, Farkkila M. Speed of onset and efficacy of zolmitriptan nasal spray in the acute treatment of migraine: a randomised, double-blind, placebo-controlled, dose ranging study versus zolmitriptan tablet. CNS Drugs 2003;17:653-667.

29. Haberer LJ, Walls CM, Lener SE, Taylor DR, McDonald SA. Distinct pharmacokinetic profile and safety of a fixed-dose tablet of sumatriptan and naproxen sodium for the acute treatment of migraine. Headache 2010;50:357-373.

30. Brandes JL, Kudrow D, Stark SR, et al. Sumatriptan-naproxen for acute treatment of migraine: a randomized trial. JAMA 2007;297:1443-1454.
31. Fedorowicz Z, Jagannath VA, Carter B. Antiemetics for reducing vomiting related to acute gastroenteritis in children and adolescents. Cochrane Database Syst Rev 2011: CD005506.

32. Carter B, Fedorowicz Z. Antiemetic treatment for acute gastroenteritis in children: an updated Cochrane systematic review with meta-analysis and mixed treatment comparison in a Bayesian framework. BMJ Open 2012;2.

33. Bigal ME, Serrano D, Buse D, Scher A, Stewart WF, Lipton RB. Acute migraine medications and evolution from episodic to chronic migraine: a longitudinal population-based study. Headache 2008;48:1157-1168.

34. Dodick D, Lipton RB, Martin V, et al. Consensus statement: cardiovascular safety profile of triptans (5-HT1B/1D agonists) in the acute treatment of migraine. Headache: J Head Face Pain 2004;44:414-425.

35. Humphrey PP, Feniuk W, Perren MJ, Connor HE, Oxford AW. The pharmacology of the novel 5-HT1-like receptor agonist, GR43175. Cephalalgia 1989;9(suppl 9): 23-33.

36. Carel I, Ghaleh B, Edouard A, et al. Comparative effects of frovatriptan and sumatriptan on coronary and internal carotid vascular haemodynamics in conscious dogs. Br J Pharmacol 2001;132:1071-1083.

37. Bates D, Ashford E, Dawson R, et al. Subcutaneous sumatriptan during the migraine aura: Sumatriptan Aura Study Group. Neurology 1994;44:1587-1592.

38. Olesen J, Diener HC, Schoenen J, Hettiarachchi J. No effect of eletriptan administration during the aura phase of migraine. Eur J Neurol 2004;11:671-677.

39. Evers S, Marziniak M, Frese A, Gralow I. Placebo efficacy in childhood and adolescence migraine: an analysis of double-blind and placebo-controlled studies. Cephalalgia 2009;29:436-444.

40. Kabbouche M. Management of pediatric migraine headache in the emergency room and infusion center. Headache 2015;55:1365-1370.

41. Kabbouche MA, Vockell AL, LeCates SL, Powers SW, Hershey AD. Tolerability and effectiveness of prochlorperazine for intractable migraine in children. Pediatrics 2001; 107:E62.

42. Richer LP, Laycock K, Millar K, et al. Treatment of children with migraine in emergency departments: national practice variation study. Pediatrics 2010;126: e150-e155.

\section{Quality Improvement: Start Small to Make Big Changes}

You deliver excellent patient care, but there is always room for improvement. In health care, quality improvement (QI) is the framework used to systematically improve the ways care is delivered to patients. Learn how to increase desired health outcomes. Browse AAN resources to help you drive change at AAN.com/view/QI.

\section{Visit the Neurology ${ }^{\circledR}$ Website at Neurology.org/N}

- More article-based content on home pages

- Streamlined menus and navigation

- Enhanced blog sections for specialty areas

- Same experience on desktop, tablet, and mobile devices

- Audio summaries of current issues

- Improved article reading experience; links more evident (pdf, analytics, social media)

- Neurology ${ }^{\circledR}$ Clinical Practice initiative "Practice Current" global surveys will be accessible across sites

f Find Neurology ${ }^{\circledR}$ on Facebook: http://tinyurl.com/neurologyfan

Follow Neurology ${ }^{\circledR}$ on Twitter: https://twitter.com/GreenJournal 


\section{Neurology}

Practice guideline update summary: Acute treatment of migraine in children and adolescents: Report of the Guideline Development, Dissemination, and Implementation Subcommittee of the American Academy of Neurology and the American Headache Society

Maryam Oskoui, Tamara Pringsheim, Yolanda Holler-Managan, et al. Neurology 2019;93;487-499 Published Online before print August 14, 2019

DOI 10.1212/WNL.0000000000008095

This information is current as of August 14, 2019

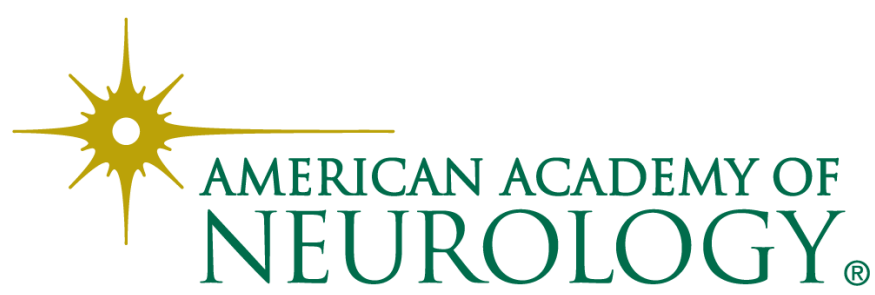




\section{Updated Information \& Services}

References

Citations

Subspecialty Collections

Errata

Permissions \& Licensing

Reprints including high resolution figures, can be found at: http://n.neurology.org/content/93/11/487.full

This article cites 39 articles, 5 of which you can access for free at: http://n.neurology.org/content/93/11/487.full\#ref-list-1

This article has been cited by 1 HighWire-hosted articles: http://n.neurology.org/content/93/11/487.full\#\#otherarticles

This article, along with others on similar topics, appears in the following collection(s):

\section{Adolescence}

http://n.neurology.org/cgi/collection/adolescence All Headache

http://n.neurology.org/cgi/collection/all_headache

All Pediatric

http://n.neurology.org/cgi/collection/all_pediatric

Migraine

http://n.neurology.org/cgi/collection/migraine

An erratum has been published regarding this article. Please see next page or:

/content/93/11/500.full.pdf /content/94/1/50.1.full.pdf

Information about reproducing this article in parts (figures,tables) or in its entirety can be found online at:

http://www.neurology.org/about/about_the_journal\#permissions

Information about ordering reprints can be found online:

http://n.neurology.org/subscribers/advertise

Neurology ${ }^{\circledR}$ is the official journal of the American Academy of Neurology. Published continuously since 1951, it is now a weekly with 48 issues per year. Copyright @ 2019 American Academy of Neurology. All rights reserved. Print ISSN: 0028-3878. Online ISSN: 1526-632X.

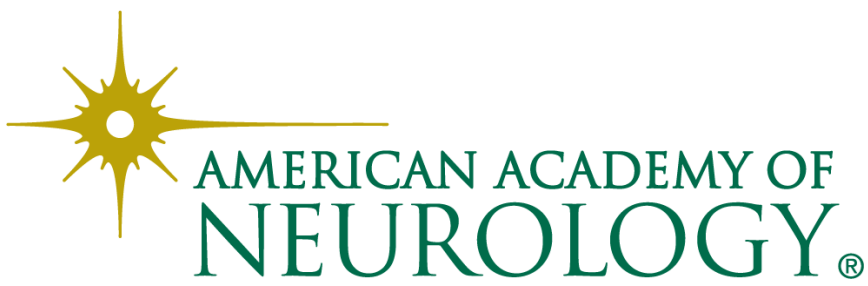




\title{
Practice guideline update summary: Pharmacologic treatment for pediatric migraine prevention
}

\author{
Report of the Guideline Development, Dissemination, and Implementation \\ Subcommittee of the American Academy of Neurology and the American
} Headache Society

Maryam Oskoui, MD, MSc, Tamara Pringsheim, MD, Lori Billinghurst, MD, MSc, Sonja Potrebic, MD, PhD, Elaine M. Gersz, David Gloss, MD, MPH\&TM, Yolanda Holler-Managan, MD, Emily Leininger, Nicole Licking, DO, Kenneth Mack, MD, PhD, Scott W. Powers, PhD, ABPP, Michael Sowell, MD, M. Cristina Victorio, MD, Marcy Yonker, MD, Heather Zanitsch, and Andrew D. Hershey, MD, PhD

Neurology ${ }^{\circledR}$ 2019;93:500-509. doi:10.1212/WNL.0000000000008105

\begin{abstract}
Objective

To provide updated evidence-based recommendations for migraine prevention using pharmacologic treatment with or without cognitive behavioral therapy in the pediatric population.
\end{abstract}

\section{Methods}

The authors systematically reviewed literature from January 2003 to August 2017 and developed practice recommendations using the American Academy of Neurology 2011 process, as amended.

\section{Results}

Fifteen Class I-III studies on migraine prevention in children and adolescents met inclusion criteria. There is insufficient evidence to determine if children and adolescents receiving divalproex, onabotulinumtoxinA, amitriptyline, nimodipine, or flunarizine are more or less likely than those receiving placebo to have a reduction in headache frequency. Children with migraine receiving propranolol are possibly more likely than those receiving placebo to have an at least 50\% reduction in headache frequency. Children and adolescents receiving topiramate and cinnarizine are probably more likely than those receiving placebo to have a decrease in headache frequency. Children with migraine receiving amitriptyline plus cognitive behavioral therapy are more likely than those receiving amitriptyline plus headache education to have a reduction in headache frequency.

\section{Recommendations}

The majority of randomized controlled trials studying the efficacy of preventive medications for pediatric migraine fail to demonstrate superiority to placebo. Recommendations for the prevention of migraine in children include counseling on lifestyle and behavioral factors that influence headache frequency and assessment and management of comorbid disorders associated with headache persistence. Clinicians should engage in shared decision-making with patients and caregivers regarding the use of preventive treatments for migraine, including discussion of the limitations in the evidence to support pharmacologic treatments.

\author{
Correspondence \\ American Academy of \\ Neurology \\ guidelines@aan.com
}

\footnotetext{
From the Departments of Pediatrics and Neurology/Neurosurgery (M.O.), McGill University, Montréal, Canada; Departments of Clinical Neurosciences, Psychiatry, Pediatrics, and Community Health Sciences (T.P.), Cumming School of Medicine, University of Calgary, Canada; Division of Neurology (L.B.), Children's Hospital of Philadelphia, PA; Neurology Department (S.P.), Southern California Permanente Medical Group, Kaiser Los Angeles; Rochester (E.M.G.), NY; Department of Neurology (D.G.), Charleston Area Medical Center, Charleston, WV; Department of Pediatrics (Neurology) (Y.H.-M.), Northwestern University Feinberg School of Medicine, Chicago, IL; St. Paul (E.L.), MN; Department of Neuroscience and Spine (N.L.), St. Anthony HospitalCentura Health, Lakewood, CO; Department of Neurology (K.M.), Mayo Clinic, Rochester, MN; Division of Behavioral Medicine \& Clinical Psychology (S.W.P., A.D.H.), Cincinnati Children's Hospital Medical Center, OH; University of Louisville Comprehensive Headache Program and University of Louisville Child Neurology Residency Program (M.S.), KY; Division of Neurology (M.C.V.), NeuroDevelopmental Science Center, Akron Children's Hospital, OH; Division of Neurology (M.Y.), Children's Hospital Colorado, Aurora; and O'Fallon (H.Z.), MO.

Go to Neurology.org/N for full disclosures. Funding information and disclosures deemed relevant by the authors, if any, are provided at the end of the article.

Approved by the American Academy of Neurology (AAN) Guideline Development, Dissemination, and Implementation Subcommittee on October 20, 2018; by the AAN Practice Committee on March 29, 2019; by the AAN Institute Board of Directors on April 10, 2019; and by the American Headache Society Board of Directors on May 1, 2019.

This practice guideline was endorsed by the Child Neurology Society on February 9, 2019; and the American Academy of Pediatrics on April 8, 2019.
} 


\section{Glossary}

AAN = American Academy of Neurology; $\mathbf{C B T}=$ cognitive behavioral therapy; $\mathbf{C I}=$ confidence interval; DVPX ER = extendedrelease divalproex sodium; FDA = Food and Drug Administration; PedMIDAS = Pediatric Migraine Disability Assessment; $\mathbf{R} \mathbf{R}=$ risk ratio; $\mathbf{S M D}=$ standardized mean differences.

This article summarizes the findings of a systematic review and practice guideline on the pharmacologic treatment of migraine prevention in children and adolescents. The unabridged practice guideline is available at https://www.aan.com/Guidelines/ home/GetGuidelineContent/978 and includes full details of the methodology used, including the risk of bias assessment for each study, meta-analysis, and confidence in evidence determinations.

This guideline systematically evaluates new evidence to answer the following clinical question: In children and adolescents with migraines, do preventive pharmacologic treatments, with or without cognitive behavioral therapy (CBT), compared with placebo, reduce headache frequency?

Migraine is common in children and adolescents, with a prevalence of $1 \%-3 \%$ in 3- to 7 -year-olds, $4 \%-11 \%$ in 7 - to 11 -yearolds, and $8 \%-23 \%$ by age 15 years. ${ }^{1}$ Diagnosis of primary headache disorders is based on clinical criteria by the International Classification of Headache Disorders, 3rd edition, by the International Headache Society. ${ }^{2}$ Most children benefit from acute migraine treatments along with behavioral and lifestyle changes for headache prevention and do not require additional pharmacologic or biobehavioral preventive treatment. ${ }^{3}$ Additional migraine prevention should be considered when headaches occur with sufficient frequency and severity and result in migraine-related disability. The Pediatric Migraine Disability Assessment (PedMIDAS) is a 6-question, self-administered scale developed and validated in children and adolescents to measure functional impact of pediatric migraine during a 3-month period. ${ }^{4}$

\section{Description of analytic process}

This guideline was developed according to the process described in the 2011 American Academy of Neurology (AAN) guideline development process manual as amended ${ }^{5}$ and is in compliance with the National Academy of Medicine (formerly Institute of Medicine) Standards for Systematic Reviews. ${ }^{6}$ A multidisciplinary author panel, consisting of headache experts, child neurologists, clinical psychologists, methodologists, and patients, was assembled by the Guideline Development, Dissemination, and Implementation Subcommittee of the AAN to write this guideline. This author panel was solely responsible for the final decisions about the design, analysis, and reporting of the guideline. The study protocol was posted for public comment according to the 2011 process manual as amended.

The authors included randomized clinical trials of migraine prevention in children aged 3-18 years and considered studies published in English and in other languages. The headache disorders in these studies were classified according to either the International Classification of Headache Disorders, 2nd edition, ${ }^{7}$ or the International Classification of Headache Disorders, 3 rd edition (beta version). ${ }^{8}$ Special populations included sexually active adolescents who were of childbearing age. Patients with episodic syndromes that may be associated with migraine, including cyclic vomiting, abdominal migraine, benign paroxysmal vertigo, and benign paroxysmal torticollis, were excluded. The systematic review included all pharmacologic interventions for the preventive treatment of migraine as well as the use of CBT in combination with pharmacologic therapy, with placebo used as the comparator. The outcome measures included change in headache frequency (defined as the reduction in number of migraine days per month, reduction of number of headache days per month, or $50 \%$ reduction in these frequencies), headache severity (defined by visual analog scale or numerical rating scale), and associated disability (PedMIDAS).

This guideline is an update of the previous guideline published in 2004 on the treatment of migraine in children and adolescents. The authors performed an initial English language literature search from December 1, 2003, to February 15, 2015, of the following databases: MEDLINE, Cochran, CINAHL, EMBASE, CDSR, DARE, CENTRAL, and an updated literature search of the same databases from January 1,2015 , to August 25, 2017. The search was conducted to find articles on both acute and preventive treatment of migraine in children and adolescents, although only trials evaluating preventive therapies were included in this systematic review. Two authors independently reviewed all abstracts and full-text articles for relevance. Articles were included if (1) $90 \%$ of participants were aged 3-18 years, (2) participants had a diagnosis of migraine, (3) the article included at least 20 participants, and (4) comparison was with placebo. The initial literature search included both pharmacologic and nonpharmacologic interventions, but due to a large number of included studies, the inclusion criteria were narrowed to only prescription pharmacologic intervention alone or in combination with CBT. Nonpharmacologic interventions, such as behavioral interventions alone or nutraceuticals, are not addressed by this guideline. Differences were reconciled by discussion; where disagreements arose, a methodologist on the panel (D.G.) adjudicated. In addition, all Class I and II studies $^{9-12}$ included in the 2004 guideline were also included. Following full-text screening, all included articles were reviewed independently by 2 authors who extracted key data from each article and determined the article's class using a standardized data extraction form that was developed for 
each clinical question by the AAN methodologists (T.P., D.G.) with input from the author panel.

The author panel reviewed the results of a comprehensive literature search (1,994 total abstracts) and identified published studies relevant to the clinical questions (the full texts of 313 articles were reviewed), which were then classified according to the AAN's 2011 evidence-based methodology, as amended. From this search and classification strategy, 11 articles ranked as Class I, II, or III were included. In addition, the 7 prevention studies from the 2004 guideline that were previously rated as Class I or II were reclassified using the 2011 process manual, as amended, and 4 rated as Class III or higher were included in the current review (figure). All 4 articles were downgraded to Class II or III when graded according to the 2011 process as amended, typically because of failure to specify concealed allocation and to state a primary outcome. ${ }^{13-17}$ The author panel based the strength of the recommendations on the grading of evidence, with consideration of costs, risks, and feasibility as well as the AAN's modifications to the Grade of Recommendations, Assessment, Development, and Evaluation. Risk ratios (RR) and standardized mean differences (SMD) and the $95 \%$ confidence interval (CI) for the outcomes of interest were calculated. For the headache responder rate outcome (proportion of participants with a $50 \%$ reduction or greater in headache frequency from baseline), we calculated the RR. We prespecified a minimal clinically important difference of 1.25 between treatment and placebo; an RR less than 1.10 was determined to be clinically unimportant. For continuous headache frequency outcomes, including the number of headache days, the number of migraine days, and migraine-related disability at endpoint, we examined the SMD. We prespecified a minimal clinically important difference in the SMD of 0.20; an SMD less than 0.1 was determined to be clinically unimportant. ${ }^{18}$

The panel formulated practice recommendations based on the strength of evidence and other factors, including axiomatic principles of care, the magnitude of anticipated health benefits relative to harms, financial burden, availability of interventions, and patient preferences. The panel assigned levels of obligation (A, B, C, U, R) to the recommendations using a modified Delphi process.

\section{Analysis of evidence}

Conclusions to the analysis of evidence are listed as follows. These conclusions are also summarized in the table.

\section{In children and adolescents with migraine, do preventive pharmacologic treatments, compared with placebo, reduce headache frequency?}

\section{Antiepileptic drugs}

Topiramate

Children and adolescents with migraine receiving topiramate are probably more likely than those receiving placebo to have a decrease in the frequency of migraine or headache days (moderate confidence in the evidence, 4 Class I studies ${ }^{19-22}$; random effect model SMD 0.391; 95\% CI 0.127-0.655; confidence in the evidence downgraded due to imprecision). There is insufficient evidence to determine whether children with migraine receiving topiramate are more or less likely than those receiving placebo to have at least a $50 \%$ reduction in headache frequency (very low confidence in the evidence; RR 1.330 [95\% CI 0.933-1.894]; confidence in the evidence downgraded due to imprecision). Children with migraine receiving topiramate are possibly no more likely than those receiving placebo to have a decrease in migraine-related disability (low confidence in the evidence, 2 Class I studies ${ }^{20,22}$; SMD 0.538 [95\% CI -0.097 to 1.174$]$; confidence in the evidence downgraded due to imprecision).

\section{Extended-release divalproex sodium (DVPX ER)}

There is insufficient evidence to determine whether children with migraine who are receiving $\operatorname{DVPXER}(250,500$, or 1,000 $\mathrm{mg} / \mathrm{d}$ ) are more or less likely than those receiving placebo to have a reduction in headache frequency (very low confidence in evidence, 1 Class II study ${ }^{23}$ downgraded for imprecision). There is insufficient evidence to determine whether children with migraine who are receiving DVPX ER are more or less likely than those receiving placebo to have at least a 50\% reduction in headache frequency (very low confidence in the evidence, 1 Class II study downgraded for imprecision; RR 0.92 [95\% CI 0.70-1.24]).

\section{Antidepressant drugs Amitriptyline}

There is insufficient evidence to determine whether children with migraine receiving amitriptyline are more or less likely than those receiving placebo to have a decrease in migraine attacks (SMD 0.11 [95\% CI -0.18 to 0.41$]$ ), to have at least a $50 \%$ reduction in headache frequency ( $\mathrm{RR} 0.86[95 \% \mathrm{CI}$ $0.68-1.13]$ ), or to have a reduction in migraine-related disability (SMD 0.03 [95\% CI -0.27 to 0.32 ]) (very low confidence in the evidence, 1 Class I study, ${ }^{20}$ confidence in the evidence downgraded for imprecision).

\section{$\boldsymbol{\beta}$-Blockers}

Propranolol

Children with migraine receiving propranolol are possibly more likely than those receiving placebo to have at least a $50 \%$ reduction in headache attacks (low confidence in the evidence, 1 Class III study ${ }^{24}$; RR 5.20 [95\% CI 1.59-17.00]; confidence in evidence upgraded due to magnitude of effect).

\section{Calcium channel blockers Flunarizine}

There is insufficient evidence to determine whether children with migraine receiving flunarizine are more or less likely than those receiving placebo to have a decrease in migraine attacks (very low confidence in evidence, 1 Class III study $^{25}$ ). Flunarizine is not available in the United States but is available in Canada. 


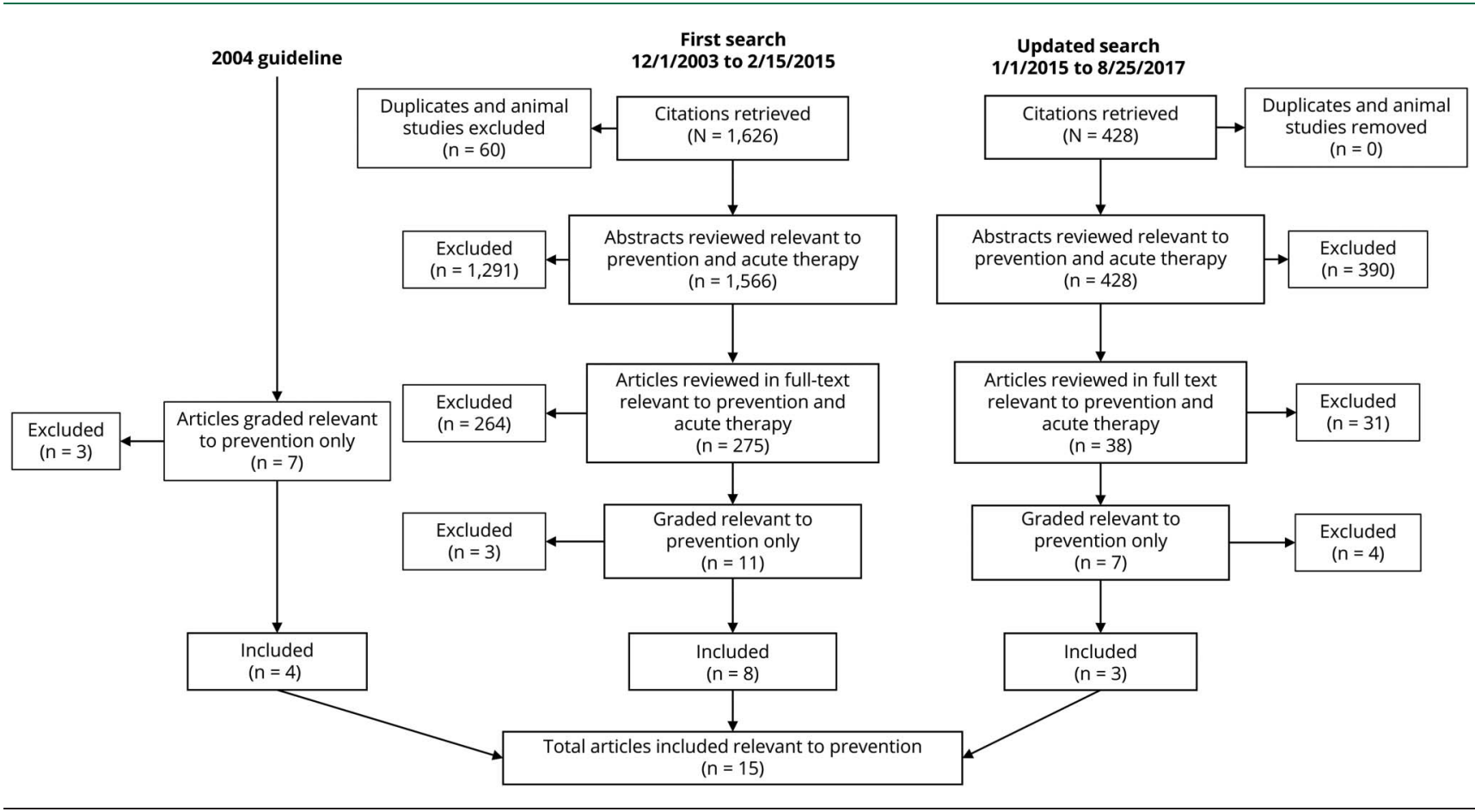

\section{Cinnarizine}

Children with migraine receiving cinnarizine are probably more likely than those receiving placebo to have a reduction in headache frequency (moderate confidence in the evidence, 1 Class II study ${ }^{26}$; SMD 0.83 [95\% CI $0.31-1.35]$; confidence in the evidence upgraded due to magnitude of effect). Children with migraine receiving cinnarizine are probably more likely than those receiving placebo to have a reduction in headache severity (moderate confidence in the evidence, 1 Class II study; SMD 0.97 [95\% CI 0.45-1.50]; confidence in the evidence upgraded due to magnitude of effect). Children with migraine receiving cinnarizine are possibly more likely than those receiving placebo to have at least a 50\% reduction in headache frequency (low confidence in the evidence; 1 Class II study; RR 1.92 [95\% CI 1.09-3.48]). Cinnarizine is not available in the United States or Canada.

\section{Nimodipine}

There is insufficient evidence to determine if children with migraine receiving nimodipine are more or less likely than those receiving placebo to have a decrease in migraine attacks (very low confidence in the evidence, 1 Class III study ${ }^{27}$ ).

\section{Neurotoxins}

\section{OnabotulinumtoxinA}

There is insufficient evidence to determine whether adolescents with chronic migraine receiving onabotulinumtoxinA, 74 units IM, are more or less likely than those receiving placebo to have a reduction in headache frequency (SMD 0.05 [95\% CI -0.39 to 0.49$]$ ) or to have at least a $50 \%$ reduction in frequency of headache days ( $R R 1.10$ [95\% CI 0.58-2.09]) (very low confidence in the evidence, 1 Class II study ${ }^{28}$ downgraded for imprecision). There is insufficient evidence to determine whether adolescents with chronic migraine receiving onabotulinumtoxinA, 155 units IM, are more or less likely than those receiving placebo to have a reduction in headache frequency (SMD 0.75 [95\% CI -0.37 to 0.51$]$ ) or to have at least a $50 \%$ reduction in frequency of headache days ( $R R \quad 0.97$ [95\% CI 0.51-1.89]) (very low confidence in the evidence, 1 Class II study $^{28}$ downgraded for imprecision).

In children and adolescents with migraine, do pharmacologic treatments combined with CBT, compared with the same pharmacologic treatments combined with a control intervention, reduce headache frequency?

Children and adolescents aged 10-17 years with chronic migraine who receive amitriptyline and CBT are more likely than those who receive amitriptyline and headache education to have a reduction in headache frequency (SMD 0.48 [95\% CI 0.14-0.82]; high confidence in the evidence; 1 Class I study, ${ }^{29}$ confidence in the evidence upgraded due to magnitude of effect) and to have at least a 50\% reduction in headache frequency ( $R R$ 1.79 [95\% CI 1.27-2.56]; high confidence in evidence, 1 Class I study, confidence in evidence upgraded due to magnitude of effect). Children and adolescents aged 10-17 years with migraine who receive amitriptyline and CBT are probably more likely than those who receive amitriptyline and headache education to have a reduction in headache-related disability (PedMIDAS SMD 
Table Outcomes and confidence in evidence

\begin{tabular}{|c|c|c|c|c|c|c|}
\hline Outcome & $\begin{array}{l}\text { High } \\
\text { confidence } \\
\text { (more likely } \\
\text { than placebo) }\end{array}$ & $\begin{array}{l}\text { Moderate } \\
\text { confidence } \\
\text { (probably more } \\
\text { likely than } \\
\text { placebo) }\end{array}$ & $\begin{array}{l}\text { Low confidence } \\
\text { (possibly more } \\
\text { likely than } \\
\text { placebo) }\end{array}$ & $\begin{array}{l}\text { Moderate } \\
\text { confidence } \\
\text { (probably no more } \\
\text { likely than placebo) }\end{array}$ & $\begin{array}{l}\text { Low confidence } \\
\text { (possibly no } \\
\text { more likely than } \\
\text { placebo) }\end{array}$ & $\begin{array}{l}\text { Very low confidence } \\
\text { (insufficient } \\
\text { evidence) }\end{array}$ \\
\hline $\begin{array}{l}\text { Decreased } \\
\text { frequency of } \\
\text { migraine or } \\
\text { headache days }\end{array}$ & $\begin{array}{l}\text { Amitriptyline } \\
(1 \mathrm{mg} / \mathrm{kg} / \mathrm{d}) \\
\text { combined with } \\
\text { CBT }\end{array}$ & $\begin{array}{l}\text { Topiramate }(100 \\
\mathrm{mg} / \mathrm{d} \text { or } 2-3 \mathrm{mg} / \mathrm{kg} / \\
\mathrm{d}) \\
\text { Cinnarizine }(1.5 \mathrm{mg} / \\
\mathrm{kg} / \mathrm{d} \text { if }<30 \mathrm{~kg} \text { or } 50 \\
\mathrm{mg} / \mathrm{d} \text { if }>30 \mathrm{~kg} \text { ) }\end{array}$ & & & & $\begin{array}{l}\text { DVPX ER }(250 \mathrm{mg} / \mathrm{d} \text {, } \\
500 \mathrm{mg} / \mathrm{d} \text {, or } 1,000 \\
\mathrm{mg} / \mathrm{d}) \\
\text { Amitriptyline }(1 \mathrm{mg} / \\
\mathrm{kg} / \mathrm{d}) \\
\text { Flunarizine }(5 \mathrm{mg} / \mathrm{d}) \\
\text { Nimodipine } \\
\text { (10-20 } \mathrm{mg}, 3 \text { times } \\
\text { a day) } \\
\text { OnabotulinumtoxinA } \\
\text { ( } 74 \cup \mathrm{IM} \text { or } 155 \mathrm{U} \mathrm{IM})\end{array}$ \\
\hline $\begin{array}{l}\text { Decreased } \\
\text { headache } \\
\text { severity }\end{array}$ & & $\begin{array}{l}\text { Cinnarizine }(1.5 \mathrm{mg} / \\
\mathrm{kg} / \mathrm{d} \text { if }<30 \mathrm{~kg} \text { or } 50 \\
\mathrm{mg} / \mathrm{d} \text { if }>30 \mathrm{~kg} \text { ) }\end{array}$ & & & & \\
\hline $\begin{array}{l}\text { At least a } \mathbf{5 0 \%} \\
\text { reduction in } \\
\text { headache } \\
\text { frequency }\end{array}$ & $\begin{array}{l}\text { Amitriptyline } \\
(1 \mathrm{mg} / \mathrm{kg} / \mathrm{d}) \\
\text { combined with } \\
\text { CBT }\end{array}$ & & $\begin{array}{l}\text { Propranolol } \\
\text { (20-40 mg, } 3 \\
\text { times a day) } \\
\text { Cinnarizine (1.5 } \\
\mathrm{mg} / \mathrm{kg} / \mathrm{d} \text { if }<30 \mathrm{~kg} \\
\text { or } 50 \mathrm{mg} / \mathrm{d} \text { if }>30 \\
\mathrm{~kg} \text { ) }\end{array}$ & & & $\begin{array}{l}\text { Topiramate }(100 \mathrm{mg} / \\
\mathrm{d} \text { or } 2-3 \mathrm{mg} / \mathrm{kg} / \mathrm{d}) \\
\text { DVPX ER }(250 \mathrm{mg} / \mathrm{d} \text {, } \\
500 \mathrm{mg} / \mathrm{d} \text {, or } 1,000 \\
\mathrm{mg} / \mathrm{d}) \\
\text { Amitriptyline }(1 \mathrm{mg} / \\
\mathrm{kg} / \mathrm{d}) \\
\text { OnabotulinumtoxinA } \\
(74 \cup \text { IM or } 155 \mathrm{U} \mathrm{IM})\end{array}$ \\
\hline $\begin{array}{l}\text { Decreased } \\
\text { migraine- } \\
\text { related } \\
\text { disability }\end{array}$ & & $\begin{array}{l}\text { Amitriptyline (1 mg/ } \\
\mathrm{kg} / \mathrm{d}) \text { combined } \\
\text { with CBT }\end{array}$ & & & $\begin{array}{l}\text { Topiramate }(100 \\
\mathrm{mg} / \mathrm{d} \text { or } 2-3 \mathrm{mg} / \\
\mathrm{kg} / \mathrm{d})\end{array}$ & $\begin{array}{l}\text { Amitriptyline (1 mg/ } \\
\mathrm{kg} / \mathrm{d} \text { ) }\end{array}$ \\
\hline
\end{tabular}

Abbreviations: CBT = cognitive behavioral therapy; DVPX ER = extended-release divalproex sodium.

0.43 [95\% CI 0.09-0.77]; moderate confidence in the evidence, 1 Class I study ${ }^{29}$ ).

\section{Practice recommendations}

\section{Counseling and education for children and adolescents with migraine and their families}

\section{Recommendation 1 rationale}

Individuals with a family history of migraine are at higher risk of developing migraine, and female sex is a risk factor of migraine that persists into adulthood. ${ }^{30}$ Disease prevention is the cornerstone of medical care. Migraine has multiple behavioral factors that influence headache frequency. Recurrent headache in adolescents is associated with being overweight, caffeine and alcohol use, lack of physical activity, poor sleep habits, and tobacco exposure. ${ }^{31}$ Depression is associated with higher headache disability in adolescents. ${ }^{32}$ Weight loss can contribute to headache reduction in children who are overweight. ${ }^{33}$ Identification and avoidance of factors that contribute to headache risk can reduce migraine frequency.

\section{Statement $1 a$}

Clinicians should counsel patients and families that lifestyle and behavioral factors may influence headache frequency (Level B).

\section{Statement $1 b$}

Clinicians should educate patients and families to identify and modify migraine contributors that are potentially modifiable (Level B).

\section{Recommendation 2 rationale}

In adults with migraine, headache on more than 6 days in a month is a risk factor for progression to chronic migraine, with medication overuse contributing to this progression. ${ }^{34}$ Taking triptans, ergotamines, opioids, and combination analgesics on more than 9 days in a month or taking overthe-counter simple analgesics on more than 14 days in a month can lead to medication overuse headache. (There is no evidence to support the use of opioids in children with migraine. Opioids are included in this rationale to be consistent with the International Classification of Headache Disorders $^{35}$ regarding medication overuse.) It has been suggested that clinicians consider preventive treatments in these populations. ${ }^{36}$ Although there are no data on this topic in pediatric populations, it is hypothesized that similar relationships between frequent headache, medication overuse, and progression to chronic migraine may occur in children. In clinical trials of pediatric migraine prevention, inclusion criteria for headache frequency were variable and included a minimum of 4 headache days per month with no maximum and 3-4 migraine attacks per month for at least 3 
months. In teenagers with migraine, those with a PedMIDAS score over 30, indicating moderate to severe migrainerelated disability, had a higher risk of mood and anxiety disorders and increased severity and frequency of headache. ${ }^{37}$

\section{Statement $2 a$}

Clinicians should discuss the potential role of preventive treatments in children and adolescents with frequent headache or migraine-related disability or both (Level B).

\section{Statement $2 b$}

Clinicians should discuss the potential role of preventive treatments in children and adolescents with medication overuse (Level B).

\section{Starting preventive treatment}

\section{Recommendation 3 rationale}

The majority of randomized controlled trials that studied the efficacy of preventive medications for pediatric migraine fail to demonstrate superiority to placebo. Pediatric migraine trial results demonstrated a high response to placebo, with $30 \%-61 \%$ of children who received placebo having had a $50 \%$ or greater reduction in headache frequency. Children and adolescents with migraine receiving topiramate are probably more likely than those receiving placebo to have a decrease in headache days and migraine attacks; however, there is insufficient evidence to determine whether children with migraine who are receiving topiramate are more or less likely than those receiving placebo to have at least a 50\% reduction in migraine frequency or headache days, and this is also the case for reduction in migraine-related disability. ${ }^{19-22}$ Children who receive propranolol are possibly more likely than those who receive placebo to have more than a $50 \%$ reduction in headache frequency. ${ }^{24,38}$ Patients receiving amitriptyline combined with $\mathrm{CBT}$ as compared with those treated with amitriptyline who receive headache education are more likely to experience a decreased headache frequency and have more than a $50 \%$ reduction in headache frequency and are probably more likely to have decreased migraine-associated disability. ${ }^{29}$ There is insufficient evidence to judge the independent effectiveness of amitriptyline on migraine prevention in children and adolescents. ${ }^{20} \mathrm{~A}$ Food and Drug Administration (FDA) black box warning regarding risk of suicidal thoughts and behavior with amitriptyline use especially in children, adolescents, and young adults is in effect at the time of this guideline. It is possible that CBT alone is effective in migraine prevention, ${ }^{10}$ and individual barriers to access may exist. ${ }^{12}$ There is insufficient evidence to evaluate the effects of flunarizine, ${ }^{25}$ nimodipine, ${ }^{27}$ valproate, ${ }^{23}$ and onabotulinumtoxin $\mathrm{A}^{28}$ for use in migraine prevention in children and adolescents. Although there is evidence that cinnarizine $^{26}$ is probably more effective than placebo for migraine prevention, this medication is not available in the United States or Canada.

\section{Statement $3 a$}

Clinicians should inform patients and caregivers that in clinical trials of preventive treatments for pediatric migraine, many children and adolescents who received placebo improved and the majority of preventive medications were not superior to placebo (Level B).

\section{Statement $3 b$}

Acknowledging the limitations of currently available evidence, clinicians should engage in shared decision-making regarding the use of short-term treatment trials (a minimum of 2 months) for those who could benefit from preventive treatment (Level B).

\section{Statement $3 \mathrm{c}$}

Clinicians should discuss the evidence for amitriptyline combined with CBT for migraine prevention, inform patients of the potential side effects of amitriptyline including risk of suicide, and work with families to identify providers who can offer this type of treatment ${ }^{12}$ (Level B).

\section{Statement 3d}

Clinicians should discuss the evidence for topiramate for migraine prevention in children and adolescents and its side effects in this population (Level B).

\section{Statement $3 e$}

Clinicians should discuss the evidence for propranolol for migraine prevention and its side effects in children and adolescents (Level B).

\section{Counseling for patients of childbearing potential}

\section{Recommendation 4 rationale}

Balancing benefit and risk is important when deciding among available medical treatments. Topiramate and valproate have well-demonstrated teratogenic effects, especially when used in polytherapy. ${ }^{39-42}$ Valproate use during pregnancy is also associated with developmental disorders in offspring. ${ }^{43,44}$ An FDA black box warning regarding fetal risk from valproate use exists as of the time of this guideline. Topiramate at a daily dose of $200 \mathrm{mg}$ or less does not interact with oral combined hormonal contraceptives; however, at higher doses it can have drug interactions that decrease their effectiveness. ${ }^{45}$ The risk of major congenital malformation in offspring of women with epilepsy taking anticonvulsants is possibly decreased by folic acid supplementation. ${ }^{46}$

\section{Statement $4 a$}

Clinicians must consider the teratogenic effect of topiramate and valproate in their choice of migraine prevention therapy recommendations to patients of childbearing potential (Level A).

\section{Statement $4 b$}

Clinicians who offer topiramate or valproate for migraine prevention to patients of childbearing potential must counsel 
these patients about potential effects on fetal/childhood development (Level A).

\section{Statement $4 \mathrm{C}$}

Clinicians who prescribe topiramate for migraine prevention to patients of childbearing potential must counsel these patients about the potential of this medication to decrease the efficacy of oral combined hormonal contraceptives, particularly at doses over $200 \mathrm{mg}$ daily (Level A).

\section{Statement $4 d$}

Clinicians who prescribe topiramate or valproate for migraine prevention to patients of childbearing potential should counsel patients to discuss optimal contraception methods with their health care provider during treatment (Level B).

\section{Statement $4 e$}

Clinicians must recommend daily folic acid supplementation to patients of childbearing potential who take topiramate or valproate (Level A).

\section{Monitoring and stopping medication}

\section{Recommendation 5 rationale}

Migraine is a chronic disorder with spontaneous remissions and relapses. Clinical trials follow patients for limited periods of time. Patients and families often inquire about the duration of treatment. There is little information about when preventive treatment should be stopped, and the risk of relapse after discontinuation varies.

\section{Statement $5 a$}

Clinicians must periodically monitor medication effectiveness and adverse events when prescribing migraine preventive treatments (Level A).

\section{Statement $5 b$}

Clinicians should counsel patients and families about risks and benefits of stopping preventive medication once good migraine control is established (Level B).

\section{Mental illness in children and adolescents with migraine}

\section{Recommendation 6 rationale}

Several studies have been performed, with inconsistent results, that evaluated the relationship between mental illness and migraine in children. A recent systematic review of prospective or retrospective longitudinal cohort studies in children examined factors associated with the onset and course of recurrent headache in children and adolescents, with recurrent headache defined as headaches occurring at least once per month. This review found high-quality evidence suggesting that children with negative emotional states, manifesting through anxiety, depression, or mental distress, are not at greater risk of developing recurrent headache; however, it found moderate-quality evidence that suggested the presence of comorbid negative emotional states in children with headache is associated with an increased risk of headache persistence in those who already experience recurrent headaches. ${ }^{30}$

\section{Statement $6 a$}

Children and adolescents with migraine should be screened for mood and anxiety disorders because of the increased risk of headache persistence (Level B).

\section{Statement $6 b$}

In children and adolescents with migraine who have comorbid mood and anxiety disorders, clinicians should discuss management options for these disorders (Level B).

\section{Putting the evidence into a clinical context}

The goal of preventive treatment is to reduce headache frequency and headache-related disability. Achieving clinically meaningful improvements should be the standard for assessing the effect of a given treatment. Involving patients and parents helps ensure that providers understand what clinically meaningful outcomes are as well as assists with treatment adherence and respects patient preferences. The choice of treatment can be guided by the presence of comorbidities (e.g., topiramate use in patients with epilepsy or the use of drugs that either decrease or increase appetite in patients with weight-related morbidity). Although topiramate is the only FDA-approved medication for migraine prevention (in children and adolescents aged 12-17 years), the current evidence base raises some doubts about whether this treatment achieves clinically meaningful outcomes beyond those obtained by placebo. There is insufficient evidence to confidently recommend this as a known efficacious preventive intervention. Some treatments with proven efficacy in adults, such as valproate for episodic migraine prevention and onabotulinumtoxinA for chronic migraine, have not shown the same efficacy in children and adolescents, and a higher pediatric placebo response rate is observed. ${ }^{47,48}$ Analysis of placebo response rates across pediatric migraine trials show that trial designs associated with a lower placebo response rate included crossover design trials, single-center studies, and small sample size, with age and sex not predictive of placebo response rates. ${ }^{49}$ The more rigorous trials have demonstrated a robust placebo response, and this response likely has a biological basis that can be potentially explored in clinical practice. $^{50}$

\section{Suggestions for future research}

Improved classification of pediatric migraine and reliable measures of outcome and disability have improved our recognition and understanding of childhood migraine and enabled more robust clinical studies. However, variation in endpoints used in trials complicates assessment and comparison of potential benefit. The presence of high placebo 
response rates in pediatric migraine demonstrates that children respond to treatment of their headache but makes identifying a therapeutic response from pharmaceutical treatments more challenging. To account for this effect, unique study designs should be taken into consideration when planning trials. New therapeutics (drugs, devices, behavioral treatments) and further well-designed studies are needed. Specifically, the efficacy of and access to the use of CBT alone needs to be informed by future well-designed randomized controlled trials. Mechanistic studies that examine mediators of improvement when a patient with migraine receives a preventive intervention or placebo could be critical in understanding how and why children with headaches get better. This type of science might also suggest innovations related to new approaches to preventive therapies.

More evidence about the benefits of behavioral changes on reducing migraine burden, in particular compared with pharmacologic prevention, would help guide treatment recommendation. Factors that contribute to headache occurrence and persistence such as biologic and psychologic factors, including mood disorders, need to be investigated to identify pathophysiologic pathways and biomarkers. This identification can then be used to guide the development of new treatments and inform patients and families of their effect on outcome.

\section{Disclaimer}

Practice guidelines, practice advisories, comprehensive systematic reviews, focused systematic reviews, and other guidance published by the AAN and its affiliates are assessments of current scientific and clinical information provided as an educational service. The information (1) should not be considered inclusive of all proper treatments, methods of care, or as a statement of the standard of care; (2) is not continually updated and may not reflect the most recent evidence (new evidence may emerge between the time information is developed and when it is published or read); (3) addresses only the question(s) specifically identified; (4) does not mandate any particular course of medical care; and (5) is not intended to substitute for the independent professional judgment of the treating provider, as the information does not account for individual variation among patients. In all cases, the selected course of action should be considered by the treating provider in the context of treating the individual patient. Use of the information is voluntary. AAN provides this information on an "as is" basis and makes no warranty, expressed or implied, regarding the information. AAN specifically disclaims any warranties of merchantability or fitness for a particular use or purpose. AAN assumes no responsibility for any injury or damage to persons or property arising out of or related to any use of this information or for any errors or omissions.

\section{Conflict of interest}

The AAN is committed to producing independent, critical, and truthful clinical practice guidelines (CPGs). Significant efforts are made to minimize the potential for conflicts of interest to influence the recommendations of this CPG. To the extent possible, the AAN keeps separate those who have a financial stake in the success or failure of the products appraised in the CPGs and the developers of the guidelines. Conflict of interest forms were obtained from all authors and reviewed by an oversight committee prior to project initiation. AAN limits the participation of authors with substantial conflicts of interest. The AAN forbids commercial participation in, or funding of, guideline projects. Drafts of the guideline have been reviewed by at least 3 AAN committees, a network of neurologists, Neurology peer reviewers, and representatives from related fields. The AAN Guideline Author Conflict of Interest Policy can be viewed at aan.com. For complete information on this process, access the 2011 AAN process manual, as amended. ${ }^{5}$

\section{Author contributions}

Dr. Oskoui: study concept and design, acquisition of data, analysis or interpretation of data, drafting/revising the manuscript, critical revision of the manuscript for important intellectual content, study supervision. Dr. Pringsheim: study concept and design, acquisition of data, analysis or interpretation of data, drafting/revising the manuscript, critical revision of the manuscript for important intellectual content, study supervision. Dr. Billinghurst: drafting/revising the manuscript, critical revision of the manuscript for important intellectual content. Dr. Potrebic: analysis or interpretation of data, drafting/revising the manuscript, critical revision of the manuscript for important intellectual content, study supervision. E.M. Gersz: critical revision of the manuscript for important intellectual content. Dr. Gloss: study concept and design, acquisition of data, analysis or interpretation of data, drafting/revising the manuscript. Dr. Holler-Managan: study concept and design, acquisition of data, drafting/revising the manuscript, critical revision of the manuscript for important intellectual content. E. Leininger: critical revision of the manuscript for important intellectual content. Dr. Licking: acquisition of data, analysis or interpretation of data, critical revision of the manuscript for important intellectual content. Dr. Mack: study concept and design, drafting/revising the manuscript, critical revision of the manuscript for important intellectual content. Dr. Powers: drafting/revising the manuscript, critical revision of the manuscript for important intellectual content. Dr. Sowell: critical revision of the manuscript for important intellectual content. Dr. Victorio: critical revision of the manuscript for important intellectual content. Dr. Yonker: critical revision of the manuscript for important intellectual content. $\mathrm{H}$. Zanitsch: critical revision of the manuscript for important intellectual content. Dr. Hershey: study concept and design, drafting/revising the manuscript, critical revision of the manuscript for important intellectual content. 


\section{Study funding}

This practice guideline was developed with financial support from the AAN. Authors who serve or have served as AAN subcommittee members or as methodologists (M.O., T.P., L.B., S.P., D.G., Y.H.M., and N.L. were reimbursed for expenses related to travel to subcommittee meetings where drafts of manuscripts were reviewed. All authors on the panel were reimbursed by the AAN for expenses related to travel to in-person meetings.

\section{Disclosure}

M. Oskoui has received research as a site principal investigator for studies in spinal muscular atrophy from Biogen, Cytokinetics, and Roche Pharmaceuticals and research support from Fonds de Recherche du Québec-Santé (FRQS), Canadian Institutes of Health Research, Cerebral Palsy Alliance Foundation, McGill University Research Institute, and SickKids Foundation; served as a consultant for Biogen, Avexis, and Roche Pharmaceuticals; and received funding for travel to quarterly meetings of the Guideline Development, Dissemination, and Implementation Subcommittee by the American Academy of Neurology (AAN). Y. Holler-Managan serves on the editorial advisory board for Neurology Now. T. Pringsheim reports no disclosures relevant to the manuscript. S. Potrebic has received funding for travel to biennial Guidelines International Network meetings by the AAN; received an honorarium and funding for travel to serve as an expert from the Center for Diagnostic Imaging and Insight Imaging (CDI) Quality Institute for work on Appropriate Use Criteria for headache imaging; and has received an honorarium from the California Technology Assessment Forum for participation as expert reviewer of the Institute for Clinical and Economic Review Calcitonin Gene-Related Peptide (CGRP) Inhibitors as Preventive Treatments for Patients with Episodic or Chronic Migraine: Effectiveness and Value Final Evidence Report. L. Billinghurst and D. Gloss report no disclosures relevant to the manuscript. A. Hershey has served on a scientific advisory board for Allergan, XOC Pharma, and Amgen; served as an editor for Headache, Cephalalgia, and the Journal of Headache and Pain; has received compensation from Allergan and MAP Pharma and currently receives compensation from Alder, Amgen, Avanir, Curelator, Depomed, Impax, Lilly, Supernus, and Upsher-Smith for serving on speakers' bureaus and as a medical consultant; has received research support from GlaxoSmithKline for serving as a Local Site PI on a study on pediatric migraine treatment, from the Migraine Research Foundation and Curelator, Inc. for serving as a principal investigator on studies on migraine genomics and diagnosis, and from the National Headache Foundation for serving as a coinvestigator on a study on migraine prognosis; has received grants from the NIH/National Institute of Neurologic Disorders and Stroke (NINDS) for serving as a coinvestigator on a study on migraine management, studies on treatment, prognosis, and diagnosis of pediatric chronic migraine and headache, and for serving as a dual principal investigator on a study on amitriptyline and topiramate in the prevention of childhood migraine; and serves as a board member of the American Headache Society. N. Licking reports no disclosures relevant to the manuscript. M. Sowell has received compensation for serving on a speakers' bureau for Amgen/Novartis Pharmaceuticals; has served as manuscript editor for Headache and the Journal of Child Neurology, on a speakers' bureau for Allergan, and as an interviewer for Neurology podcasts; served as site principal investigator for the CHAMP (Childhood and Adolescent Migraine Prevention) study, for which he received research support from NINDS; and receives research support from Impax Pharmaceuticals. M.C. Victorio is the site primary investigator for a childhood and adolescent migraine prevention study funded by the NIH and site investigator for a pediatric migraine treatment study funded by Impax Laboratories (both studies were contracted through Akron Children's Hospital); has received funding for travel to meetings of the Registry Committee and Quality and Safety Subcommittee by the AAN; has received honoraria for authoring and coauthoring chapters in the Merck Manual and for authoring an article in Pediatric Annals; and performs the following clinical procedures in her practice: onabotulinumtoxinA injection for chronic migraine $(2 \%)$ and peripheral nerve block injections (2\%). E. Gersz and E. Leininger report no disclosures relevant to the manuscript. $\mathrm{H}$. Zanitsch has received financial compensation from the Patient-Centered Outcomes Research Institute and Peer Reviewed Medical Research Program and serves as a volunteer advocate for the National Headache Foundation. M. Yonker has served on a scientific advisory board for AMGEN and for Upsher-Smith Pharmaceuticals; has served as a reviewer for Cephalalgia, Headache, Pediatrics, and the Journal of the Child Neurology Society; has received research support as a primary investigator from AstraZeneca, Allergan, Avanir, and NINDS; has received funding for travel from the American Headache Society for serving as a presenter at the Scottsdale Headache Symposium; and serves as a consultant to Impax. Dr. Kenneth Mack has served as an advisor for AMGEN; receives publishing royalties from UpToDate; performs botulinum toxin injections for headache treatment as 5\% of his clinical effort; and serves as a member of the Neurology ${ }^{\otimes}$ editorial board. S. Powers has received funding from the NIH, Migraine Research Foundation, and National Headache Foundation; and has served as a manuscript reviewer for Headache, Cephalalgia, Pain, Journal of Pain, JAMA Pediatrics, and Pediatrics. Go to Neurology.org/N for full disclosures.

\section{Publication history}

Received by Neurology December 21, 2018. Accepted in final form May 14, 2019.

\section{References}

1. Victor TW, Hu X, Campbell JC, Buse DC, Lipton RB. Migraine prevalence by age and sex in the United States: a life-span study. Cephalalgia 2010;30: 1065-1072.

2. Headache Classification Committee of the International Headache Society (IHS). The International Classification of Headache Disorders, 3rd edition (beta version). Cephalalgia 2018;38:1-211.

3. Lopez J, Bechtel KA, Rothrock JF. Pediatric headache [online]. Available at: emedicine.medscape.com/article/2110861-overview. Accessed February 28, 2015.

4. Hershey AD, Powers SW, Vockell AL, LeCates S, Kabbouche MA, Maynard MK. PedMIDAS: development of a questionnaire to assess disability of migraines in children. Neurology 2001;57:2034-2039. 
5. American Academy of Neurology. Clinical Practice Guideline Process Manual, 2011 ed. St. Paul: American Academy of Neurology; 2011.

6. Institute of Medicine. Finding what Works in Health Care: Standards for Systematic Reviews. Washington, DC:Institute of Medicine; 2011.

7. Headache Classification Subcommittee of the International Headache Society. The International Classification of Headache Disorders: 2nd edition. Cephalalgia 2004; 24(suppl 1):9-160.

8. Headache Classification Committee of the International Headache Society. The International Classification of Headache Disorders, 3rd edition (beta version). Cephalalgia 2013;33:629-808.

9. Ng QX, Venkatanarayanan N, Kumar L. A systematic review and meta-analysis of the efficacy of cognitive behavioral therapy for the management of pediatric migraine. Headache 2017;57:349-362.

10. Eccleston C, Palermo TM, Williams ACdC, et al. Psychological therapies for the management of chronic and recurrent pain in children and adolescents. Cochrane Database Syst Rev 2014;5:CD003968.

11. Kroon Van Diest AM, Ernst MM, Vaughn L, Slater S, Powers SW. CBT for pediatric migraine: a qualitative study of patient and parent experience. Headache 2018;58: 661-675.

12. Ernst MM, O'Brien HL, Powers SW. Cognitive-behavioral therapy: how medical providers can increase patient and family openness and access to evidence-based multimodal therapy for pediatric migraine. Headache 2015;55:1382-1396.

13. Olness K, MacDonald JT, Uden DL. Comparison of self-hypnosis and propranolol in the treatment of juvenile classic migraine. Pediatrics 1987;79:593-597.

14. Ueberall MA, Wenzel D. Intranasal sumatriptan for the acute treatment of migraine in children. Neurology 1999;52:1507-1510.

15. Sills $\mathrm{M}$, Congdon P, Forsythe I. Clonidine and childhood migraine: a pilot and double-blind study. Dev Med Child Neurol 1982;24:837-841.

16. Sillanpaa M. Clonidine prophylaxis of childhood migraine and other vascular headache: a double blind study of 57 children. Headache 1977;17:28-31.

17. Gillies D, Sills M, Forsythe I. Pizotifen (Sanomigran) in childhood migraine: a doubleblind controlled trial. Eur Neurol 1986;25:32-35.

18. Cohen J. Statistical Power for the Behavioural Sciences. 2nd ed. Hillsdale, NJ: Erlbaum; 1988.

19. Lewis D, Winner P, Saper J, et al. Randomized, double-blind, placebo-controlled study to evaluate the efficacy and safety of topiramate for migraine prevention in pediatric subjects 12 to 17 years of age. Pediatrics 2009;123:924-934.

20. Powers SW, Coffey CS, Chamberlin LA, et al. Trial of amitriptyline, topiramate, and placebo for pediatric migraine. N Engl J Med 2017;376:115-124.

21. Winner P, Pearlman EM, Linder SL, et al. Topiramate for migraine prevention in children: a randomized, double-blind, placebo-controlled trial. Headache 2005;45: 1304-1312.

22. Lakshmi CV, Singhi P, Malhi P, Ray M. Topiramate in the prophylaxis of pediatric migraine: a double-blind placebo-controlled trial. J child Neurol 2007;22:829-835.

23. Apostol G, Cady RK, Laforet GA, et al. Divalproex extended-release in adolescent migraine prophylaxis: results of a randomized, double-blind, placebo-controlled study. Headache 2008;48:1012-1025.

24. Ludvigsson J. Propranolol used in prophylaxis of migraine in children. Acta Neurol Scand 1974;50:109-115.

25. Sorge F, De Simone R, Marano E, Nolano M, Orefice G, Carrieri P. Flunarizine in prophylaxis of childhood migraine: a double-blind, placebo-controlled, crossover study. Cephalalgia 1988;8:1-6.

26. Ashrafi MR, Salehi S, Malamiri RA, et al. Efficacy and safety of cinnarizine in the prophylaxis of migraine in children: a double-blind placebo-controlled randomized trial. Pediatr Neurol 2014;51:503-508.

27. Battistella PA, Ruffilli R, Moro R, et al. A placebo-controlled crossover trial of nimodipine in pediatric migraine. Headache 1990;30:264-268.

28. Allergan. 191622-103 BOTOX $^{\circledast}$ (Botulinum Toxin Type A) Purified Neurotoxin Complex as Headache Prophylaxis in Adolescents (Children 12 to $<18$ Years of Age) With Chronic Migraine. Available at https://clinicaltrials.gov/ct2/show/results/
NCT01662492?view=results. Published September 5, 2017. Accessed September 6, 2017.

29. Powers SW, Kashikar-Zuck SM, Allen JR, et al. Cognitive behavioral therapy plus amitriptyline for chronic migraine in children and adolescents: a randomized clinical trial. JAMA 2013;310:2622-2630.

30. Huguet A, Tougas ME, Hayden J, et al. Systematic review of childhood and adolescent risk and prognostic factors for recurrent headaches. J Pain 2016;17:855-873 e858.

31. Robberstad L, Dyb G, Hagen K, Stovner LJ, Holmen TL, Zwart JA. An unfavorable lifestyle and recurrent headaches among adolescents: the HUNT study. Neurology 2010;75:712-717.

32. Amouroux R, Rousseau-Salvador C, Pillant M, Antonietti JP, Tourniaire B, Annequin D. Longitudinal study shows that depression in childhood is associated with a worse evolution of headaches in adolescence. Acta Paediatr 2017;106:1961-1965.

33. Hershey AD, Powers SW, Nelson TD, et al. Obesity in the pediatric headache population: a multicenter study. Headache 2009;49:170-177.

34. Katsarava Z, Schneeweiss S, Kurth T, et al. Incidence and predictors for chronicity of headache in patients with episodic migraine. Neurology 2004;62:788-790.

35. Headache Classification Committee of the International Headache Society. The International Classification of Headache Disorders, 3rd edition (beta version). Cephalalgia 2013;33:629-808.

36. Alstadhaug $\mathrm{KB}$, Ofte $\mathrm{HK}$, Kristoffersen ES. Preventing and treating medication overuse headache. Pain Rep 2017;2:e612.

37. Fuh JL, Wang SJ, Lu SR, Liao YC, Chen SP, Yang CY. Headache disability among adolescents: a student population-based study. J Head Face Pain 2010;50:210-218.

38. Forsythe WI, Gillies D, Sills MA. Propanolol (Inderal) in the treatment of childhood migraine. Dev Med Child Neurol 1984;26:737-741.

39. Vajda FJ, O’Brien TJ, Lander CM, Graham J, Eadie MJ. Antiepileptic drug combinations not involving valproate and the risk of fetal malformations. Epilepsia 2016;57: 1048-1052.

40. Tomson T, Battino D, Bonizzoni E, et al. Dose-dependent teratogenicity of valproate in mono- and polytherapy: an observational study. Neurology 2015;85:866-872.

41. Holmes LB, Mittendorf R, Shen A, Smith CR, Hernandez-Diaz S. Fetal effects of anticonvulsant polytherapies: different risks from different drug combinations. Arch Neurol 2011;68:1275-1281.

42. Hunt S, Russell A, Smithson WH, et al. Topiramate in pregnancy: preliminary experience from the UK epilepsy and pregnancy register. Neurology 2008;71:272-276.

43. Christensen J, Gronborg TK, Sorensen MJ, et al. Prenatal valproate exposure and risk of autism spectrum disorders and childhood autism. JAMA 2013;309:1696-1703.

44. Bromley RL, Calderbank R, Cheyne CP, et al. Cognition in school-age children exposed to levetiracetam, topiramate, or sodium valproate. Neurology 2016;87: 1943-1953.

45. Doose DR, Wang SS, Padmanabhan M, Schwabe S, Jacobs D, Bialer M. Effect of topiramate or carbamazepine on the pharmacokinetics of an oral contraceptive containing norethindrone and ethinyl estradiol in healthy obese and nonobese female subjects. Epilepsia 2003;44:540-549.

46. Harden CL, Pennell PB, Koppel BS, et al. Practice parameter update: management issues for women with epilepsy: focus on pregnancy (an evidence-based review): vitamin $\mathrm{K}$, folic acid, blood levels, and breastfeeding: report of the Quality Standards Subcommittee and Therapeutics and Technology Assessment Subcommittee of the American Academy of Neurology and American Epilepsy Society. Neurology 2009; 73:142-149.

47. Freitag FG, Collins SD, Carlson HA, et al. A randomized trial of divalproex sodium extended-release tablets in migraine prophylaxis. Neurology 2002;58:1652-1659.

48. Dodick DW, Turkel CC, DeGryse RE, et al. OnabotulinumtoxinA for treatment of chronic migraine: pooled results from the double-blind, randomized, placebocontrolled phases of the PREEMPT clinical program. Headache 2010;50:921-936.

49. Evers S, Marziniak M, Frese A, Gralow I. Placebo efficacy in childhood and adolescence migraine: an analysis of double-blind and placebo-controlled studies. Cephalalgia 2009;29:436-444.

50. Faria V, Linnman C, Lebel A, Borsook D. Harnessing the placebo effect in pediatric migraine clinic. J Pediatr 2014;165:659-665.

\section{Subspecialty Alerts by E-mail!}

Customize your online journal experience by signing up for e-mail alerts related to your subspecialty or area of interest. Access this free service by clicking on the "My Alerts" link on the home page. An extensive list of subspecialties, methods, and study design choices will be available for you to choose from-allowing you priority alerts to cutting-edge research in your field! 


\section{Practice guideline update summary: Acute treatment of migraine in} children and adolescents

Report of the Guideline Development, Dissemination, and Implementation Subcommittee of the American Academy of Neurology and the American Headache Society

Neurology ${ }^{\circledR} 2020 ; 94: 50$. doi:10.1212/WNL.0000000000008728

In the Special Article "Practice guideline update summary: Acute treatment of migraine in children and adolescents: Report of the Guideline Development, Dissemination, and Implementation Subcommittee of the American Academy of Neurology and the American Headache Society" by Oskoui et al., ${ }^{1}$ the following disclaimer/publication statement should have been included: "These guidelines were jointly developed by the American Academy of Neurology Institute and American Headache Society. This article was peer reviewed and first published by Neurology, and subsequently published in Headache." The publisher regrets the error.

\section{Reference}

1. Oskoui M, Pringsheim T, Holler-Managan Y, et al. Practice guideline update summary: acute treatment of migraine in children and adolescents: report of the Guideline Development, Dissemination, and Implementation Subcommittee of the American Academy of Neurology and the American Headache Society. Neurology 2019;93:487-499.

\section{Practice guideline update summary: Pharmacologic treatment for pediatric migraine prevention}

Report of the Guideline Development, Dissemination, and Implementation Subcommittee of the American Academy of Neurology and the American Headache Society

Neurology ${ }^{\circledR} 2020 ; 94: 50$. doi:10.1212/WNL.0000000000008750

In the Special Article "Practice guideline update summary: Pharmacologic treatment for pediatric migraine prevention: Report of the Guideline Development, Dissemination, and Implementation Subcommittee of the American Academy of Neurology and the American Headache Society" by Oskoui et al., ${ }^{1}$ the following disclaimer/publication statement should have been included: "These guidelines were jointly developed by the American Academy of Neurology Institute and American Headache Society. This article was peer reviewed and first published by Neurology, and subsequently published in Headache.” The publisher regrets the error.

\section{Reference}

1. Oskoui M, Pringsheim T, Billinghurst L, et al. Practice guideline update summary: pharmacologic treatment for pediatric migraine prevention: report of the Guideline Development, Dissemination, and Implementation Subcommittee of the American Academy of Neurology and the American Headache Society. Neurology 2019;93:500-509. 